\title{
Empresarios, política y sociedad en América Latina: el caso de México
}

\author{
Carlos Alba Vega *
}

\section{Resumen}

El texto examina las relaciones entre los empresarios y el Estado en México en una perspectiva de largo plazo, para mostrar que la participación política de los actores económicos tiene algunos rasgos comunes pero también singularidades respecto a los empresarios de otros países de América Latina. El desarrollo del trabajo está guiado por cinco preguntas: ¿Qué características tienen los empresarios por enmarcarse en un sistema político que surge de una revolución social? ¿Qué importancia tiene el Consejo Mexicano de Hombres de Negocios en las relaciones entre los empresarios y el Estado? ¿Cómo participan los empresarios en la transición política? ¿Cuáles fueron las conductas de los empresarios en las últimas elecciones presidenciales de 2006? ¿Cómo ha afectado la crisis económica a las empresas y los empresarios en México, y a la sociedad en su conjunto?

Palabras-clave: empresarios y política, empresarios y transición política, grupos de poder, empresarios y la crisis.

\section{Introducción}

os empresarios de América Latina experimentaron profundas Ltransformaciones como actores económicos y políticos a lo largo del siglo veinte y hasta ahora. Cada época y coyuntura histórica regional, nacional e internacional influyeron en sus empresas y sus conductas. Podría afirmarse que existen ciertos rasgos comunes básicos a todos ellos, pero también profundas diferencias derivadas de factores históricos, demográficos, geoeconómicos y políticos. El

* Profesor-Investigador del Centro de Estudios Internacionales de El Colegio de México (Cidade do México). Endereço eletrônico: calba@colmex.mx. 
modelo primario exportador permitió la emergencia de varios de ellos en algunos sectores de actividad: productores y exportadores de carne, trigo, oleaginosas y lana en Argentina; empresarios del estaño en Bolivia, productores y exportadores de café y azúcar en Brasil, actores ligados a empresas mineras del cobre en Chile; cafetaleros en Colombia, cultivadores de azúcar y tabaco en Cuba; mineros y productores de carne, henequén y algodón en México.

La gran recesión mundial de 1929 dio término a este modo de desarrollo y se inició una nueva época nacionalista de "desarrollo hacia adentro" en la que el Estado se convirtió en un agente de desarrollo, y aunque facilitó la emergencia y expansión de los empresarios en diversas actividades, en la medida que el modelo se fue agotando por contradicciones internas y por su fuerte dependencia de las importaciones de bienes intermedios y de capital y el Estado intervino en forma creciente en la economía, aparecieron discrepancias profundas entre ambos actores, al grado que en muchos países los empresarios se aliaron con fuerzas políticas y militares a favor de un cambio. Sin embargo también participaron en ciertos momentos y contextos por la apertura democrática.

Las relaciones entre los empresarios y el Estado en los distintos países de América Latina manifiestan puntos de convergencia y divergencia, dependiendo de múltiples factores. El caso de las relaciones de los empresarios y el Estado en México en general, y de su participación política en particular es sui generis por varias razones: es el país latinoamericano más afectado por la actual crisis económica; es el único que hace frontera, con cerca de 3700 kilómetros, con Estados Unidos, el país más poderoso del mundo; el Estado mexicano emergió de una revolución social y política (1910) de gran envergadura. Todo eso ha engendrado un empresariado con características particulares, aunque también con elementos comunes a otros empresarios latinoamericanos.

En este trabajo nos proponemos examinar en una perspectiva de largo plazo algunas de las singularidades de estos hombres de negocios. Las preguntas que guían nuestro análisis son las siguientes: ¿Qué características tienen los empresarios por enmarcarse en un sistema político que surge de una revolución social? ¿Qué importancia tiene el Consejo Mexicano de Hombres de Negocios en 
las relaciones entre los empresarios y el estado? ¿Cómo participan los empresarios en la transición política? ¿Cuáles fueron las conductas de los empresarios en las últimas elecciones presidenciales de 2006? ¿Cómo ha afectado la crisis económica a las empresas y los empresarios en México, y a la sociedad en su conjunto?

Para responder a estas preguntas el trabajo está dividido en cinco partes. En la primera ofreceremos una visión de largo plazo sobre la presencia y el poder de los empresarios en el contexto de los gobiernos post revolucionarios. La segunda aborda al Consejo Mexicano de Hombres de Negocios (CMHN) para mostrar la importancia que ha tenido en México en ciertos momentos cruciales. En la tercera observaremos la participación de los empresarios en la transición democrática. En la cuarta analizaremos las conductas de los empresarios en las elecciones presidenciales de 2006. En quinta y última examinaremos algunos impactos que la presente crisis mundial tiene en la economía, la sociedad y las distintas regiones de México.

\section{Los empresarios después de la Revolución Mexi- cana}

El inicio y fin siglo XX marcaron un ciclo completo en el papel que desempeñaron los empresarios. Lo iniciaron a la defensiva a causa de la Revolución, la que tuvo adeptos y detractores entre ellos (Herrera Collado, 1996). Una parte de los empresarios, sobre todo los hacendados norteños (con la excepción de los del estado de Chihuahua) participó en la Revolución para pugnar por un cambio político (WASSERMANN, 1988; KATZ, 1998). Otra parte, en cambio, se aferraba al antiguo régimen, brindó su solidaridad a Victoriano Huerta (1913-1914) y cuando éste fue derrotado, se vio forzada a exiliarse en los Estados Unidos.

Venustiano Carranza (ago.1914 - nov.1914; 1915-1917; 1917-1920) derrotó militar y políticamente a los ejércitos populares de Francisco Villa y Emiliano Zapata, pero se vio obligado a incorporar en la Constitución de 1917 varias de sus banderas sociales y políticas que en esa época aparecían como muy radicales, en especial el artículo 27 sobre la reforma agraria y las limitaciones a la propiedad privada, y el artículo 123 sobre los derechos laborales. 
El régimen emanado de la Revolución se forjó una imagen ambivalente de los empresarios. Por una parte, los empresarios representaban a la sociedad moderna a la que aspiraban. Por la otra, su propia acción en los espacios agrícolas más modernizados había destruido antiguos derechos agrarios en unas zonas, mientras que en otras los empresarios crecían a expensas de las condiciones de los trabajadores textileros o mineros.

En la cultura europea, ya que no en la estadounidense, el desprecio y hasta el odio a la burguesía como pasión movilizadora había recorrido el siglo XIX para llegar a su apogeo en el siglo XX. Bolchevismo y fascismo coincidieron en identificarla como un enemigo a vencer. En México, casi carente de este sector, a partir de la Revolución solo su fracción más visible fue puesta en cuestión, y más tarde, durante la presidencia de Lázaro Cárdenas (1934-1940) en los años treinta, sería debilitada y destruida: los hacendados (ALBA VEGA, 2001).

La Revolución Mexicana ubicó al empresariado más cerca de la Revolución Francesa, que le abrió las puertas para que entrara en sociedad con derecho propio, aunque desde entonces recibiera las mayores críticas de derecha y de izquierda, que de la Revolución Soviética, la cual le negó todo derecho a existir.

Los empresarios mexicanos permanecieron por mucho tiempo alejados de la acción política directa. De un lado, según muchos de ellos, la política era algo sucio en donde no había que meterse. Del otro, en el proceso de formación del nuevo Estado, muy pocos empresarios ingresarían a la clase política, como había ocurrido durante el siglo XIX, cuando era frecuente que los gobernadores fueran hombres de negocios de diversos tipos: de Santiago Vidaurri en Nuevo León (CERUTTI, 1983 y 2000), a José Palomar en Jalisco (Alba Vega, 2003) o Luis Terrazas en Chihuahua (WASSERMANN, 1988; KATZ, 1998). Después de la Revolución, más frecuente era que a partir del Estado se convirtieran en prósperos empresarios. (HERRERA COLLADO, 1996; KAUFMAN PURCELL, 1975; LABASTIDA, 1972, 1986; CAMP, 1989), algunos ejemplos de ellos son los casos de Aarón Sáenz y los de los presidentes de México: Abelardo L. Rodríguez (1932-1934) y Miguel Alemán Valdés (1946-1952), así como el de la familia del presidente Plutarco Elías Calles (1924-1928). 
Aunque a principios del siglo XX eran una clase social débil, el nuevo gobierno constitucionalista de Carranza los necesitaba y los buscó a través de Pani, el ministro del trabajo, para proponerles que se organizaran. Así nacieron, en gran parte por iniciativa del Estado, las dos confederaciones que perviven hasta la fecha: la de comerciantes, la CONCANACO (1917), y la de industriales, la CONCAMIN (1918) (ARRIOLA, 1988; TIRADO, 2006).

Las confederaciones fueron útiles en muchos sentidos para ambas partes, pero los empresarios no siempre las perciben como plenamente suyas. Diez años después de creadas, los industriales de Monterrey, los empresarios más consolidados del país desde antes de la Revolución, crearon otra organización con características distintas: la Confederación Patronal de la República Mexicana (Coparmex, 1929), constituida en sindicato patronal organizado como fuerza autónoma, independiente del Estado, donde a partir de entonces se escucha la voz propia de los empresarios (REYES PONCE, 1979). Surge para hacer frente al ímpetu del Estado social de los años veinte y a su injerencia en la economía, el cual se expresó en el debate sobre la iniciativa gubernamental de modificar el Código Federal del Trabajo, que en 1931 daría lugar a la Ley Federal del Trabajo. Al paso del tiempo, la Coparmex mostraría su papel crucial como red conscientizadora, instigadora y orientadora del descontento de los empresarios. Desde esta institución los empresarios pasaron de meros actores económicos a sujetos políticos (TIRADO, 1984; BUENDÍA LAREDO, 1989).

Desde la Revolución los empresarios no habían tenido una verdadera confrontación con el Estado hasta que el General Cárdenas ocupó la presidencia (1934-1940). Con la aplicación intensa de la Reforma Agraria vieron amenazado el principio de la propiedad privada, que en muchos casos tocó sus propios intereses, los de sus familiares o amigos. Además, la nueva Ley de Expropiación de 1936 confería al Estado mayor capacidad de intervención en la economía (JUÁREZ, 1982 y 1983). Aparte, el apoyo que el gobierno cardenista brindó a las reivindicaciones obreras, con las crecientes demandas y huelgas de los trabajadores, avivó la tensión. Asimismo, como a otros sectores sociales, les preocupaba el curso que tomaba la educación, ya que al modificarse el artículo 3o. de la Constitución se declaraba 
que la educación que impartiera el estado sería socialista. El descontento ante la reforma agraria, la movilización obrera y la educación socialista ofrecieron a la Coparmex una bandera para hacer proselitismo y expandirse en los estados. Sin embargo, el cambio sexenal que llevó a la presidencia a Ávila Camacho (1940-1946) cambió la orientación de la educación e hizo prevalecer la idea de fomentar no la lucha sino la conciliación de clases. A partir de entonces, se dio un fuerte acercamiento entre los empresarios y el Estado que llegó a una de sus cimas con Miguel Alemán (1946-1952) en la presidencia (TORRES, 1984; ZABLUDOWSKI, 1984). Las principales leyes que habían sido impugnadas desde Cárdenas se modifican: el artículo 27 sobre la Reforma Agraria y el Artículo 3o sobre la educación. Aunque después se presentaron algunos desencuentros, desde 1940 hasta 1970 ocurrió un notable acercamiento entre el sector privado y el Estado, a tal grado que inhibió la expansión de la Coparmex y provocó su estancamiento (REYES PONCE, 1979).

El cambio de modelo de desarrollo, de uno primario exportador a otro nacionalista orientado hacia adentro, denominado de industrialización por sustitución de importaciones en América Latina, llevaron al Estado a intervenir en forma creciente en la economía como agente de desarrollo (TOURAINE, 1976) y con ello provocaría un creciente malestar en un sector empresarial que había adquirido fuerza y coherencia en gran parte gracias al apoyo gubernamental.

Durante el largo período que duró el modelo de substitución de importaciones, el Estado brindó apoyos excepcionales para que el sector privado creciera y se consolidara en todos los sectores económicos a través de estímulos, subsidios, precios preferenciales otorgados por las empresas públicas, protección arancelaria y muchas otras facilidades.

Este modelo de expansión industrial protegido, que en algunos sectores adquirió características oligopólicas, a fuerza de perdurar indefinidamente, ofreció poco estímulo a la competitividad y se hizo dependiente para su desarrollo del apoyo del Estado, lo que reforzó las relaciones corporativas y heterónomas de vastos sectores del empresariado en la esfera de la representación política de sus intereses. 
Sin embargo, por las mismas características del modelo, el Estado no solo ofreció ventajas a los empresarios, sino que llegado cierto momento se involucró directamente en la economía como empresario en el campo reservado originalmente para la iniciativa privada. Primero lo haría en áreas consideradas estratégicas, como el petróleo, la petroquímica básica y la electricidad. Después se introduciría en la industria siderúrgica, en la minera y en una amplia variedad de empresas, algunas en bancarrota, otras, con graves problemas laborales.

El origen del Estado mexicano tuvo también consecuencias sobre la formulación de las políticas públicas, en la medida que estas se efectuaron subordinando planes y reglas preestablecidas, búsqueda de consensos o eficiencia técnica ante los vaivenes de la coyuntura económica, la correlación política de fuerzas o la voluntad centralizada del presidente, sin contrapeso de los otros poderes (LUNA LEDEZMA, 1992, p.132).

Durante muchas décadas los empresarios, aún los más grandes que pertenecían al CMHN, elogiaron abiertamente la estabilidad política que había logrado el Partido Revolucionario Institucional, PRI; incluso llegaron a ofrecerla en algunos foros como un ejemplo, en contraposición a los regímenes de otros países de América Latina. En lo político manifestaban un acuerdo tácito y el grado de democracia alcanzado en esa época no parecía preocuparles. Lo que los inquietó fue cuando el Estado intervino en forma creciente en la economía. Su descontento se expresó durante muchos años solo a nivel discursivo. En la coyuntura de cada cambio de sexenio, los empresarios organizados expresaban declaraciones públicas o manifiestos periodísticos en defensa de la libre empresa, destinados al nuevo presidente. Desde finales de los años cincuenta, nuevamente los empresarios más importantes y mejor organizados, pero ahora desde la ciudad de México, empezaron a hacer una política distinta. Sus tres acciones principales en esta época tuvieron lugar durante la administración de López Mateos: la creación del Consejo Nacional de la Publicidad (24 de noviembre de 1959) y del Consejo Mexicano de Relaciones Públicas (1962), que más tarde sería el Consejo Mexicano de Hombres de Negocios, y la declaración del famoso desplegado: “¿Por cuál camino señor presidente?”. Con la primera institución los 
empresarios expresan su capacidad de organización y su entrada en el campo estratégico de la comunicación social, para no limitarse a la producción y distribución de bienes y servicios. Este Consejo participaría activamente desde la administración de Echeverría en la defensa de la libre empresa.

Con el desplegado periodístico promovido también por los principales empresarios de México y firmado por la CONCAMIN, la Concanaco y la Coparmex, se manifiesta la intranquilidad de la iniciativa privada ante la política económica que, según la declaración, contradice los principios económicos consagrados en la Constitución ${ }^{1}$.

Con el título de Consejo Mexicano de Relaciones Públicas surge a principios de los años sesenta una organización que ya con el nombre de Consejo Mexicano de Hombres de Negocios sus acciones serán cruciales para entender el sistema político mexicano desde la segunda mitad del siglo XX. De ella nos ocuparemos en la segunda parte.

\section{El Consejo Mexicano de Hombres de Negocios}

Tal vez no exista en América Latina una organización del tipo del Consejo Mexicano de Hombres de Negocios y esta puede ser una de las diferencias que habrá que hacer notar entre las organizaciones empresariales de México y las de los demás países ${ }^{2}$. Nació el 13 de noviembre de 1962 como una organización de cabildeo informal (VALDÉS UGALDE, 1997), a la cual se accede solo por invitación; alberga a la elite constituida por los 40 empresarios más acaudalados y es la organización económica y grupo de presión más poderoso de México. Por muchos años funcionó con extrema discreción, sin burocracia, casi de manera secreta. Ha mantenido una cercanía con los representantes del poder político al más alto nivel, aún en tiempos de crisis o conflicto con el Estado. Eso le ha permitido

1 El desplegado periodístico titulado “¿Por cuál camino señor Presidente?” fue redactado por el señor Juan Sánchez Navarro, y firmado y publicado por la Concamin, la Concanaco y la Coparmex el 24 de noviembre de 1960. Entrevista con Juan Sánchez Navarro, México, D.F., noviembre de 1996

2 Las principales fuentes para acercase a esta organización son: Briz Garizurieta, 1992 y 2006 y Ortiz Rivera, 1998. 
influir en decisiones importantes en materia económica. Y también ha podido presionar en ciertos momentos ante determinadas políticas a favor de sus intereses. En el ámbito político, ha participado en la pre-selección de candidatos a la presidencia de la presidencia de la republica desde Gustavo Díaz Ordaz (1964 1970) a través de la "pasarela" y en la designación de cargos importantes en materia económica, como el del Secretario de Hacienda o el del Gobernador del Banco de México. Ha sido, además, un espacio privilegiado del gobierno para sondear la opinión de los grandes empresarios ante determinadas decisiones y políticas públicas y donde se realiza el lobbying (cabildeo) necesario para llevarlas a término. El CMHN desempeñó un papel esencial en el cambio de modelo económico adoptado en los años ochenta: la liberalización, las privatizaciones y la desregulación, por ejemplo en la Ley de Inversión extranjera (BRIZ GARIZURIETA, 2006).

Es también una peculiaridad de este grupo de la élite de empresarios, el hecho de reunir a todos los sectores de actividad económica: la minería, el agropecuario, el industrial, el comercial, el bancario y financiero.

Su liderazgo en los negocios se refuerza por las conexiones de sus empresas con el resto de los grandes empresarios mexicanos a través de la producción, distribución, consumo o financiamiento de los bienes y servicios relacionados con ellos. Por encima de esos, en muchos casos sus miembros consolidan sus fortunas por medio de negocios compartidos o por relaciones de parentesco. Ese poder crecido les permite tener "derecho de picaporte" o acceso fácil con la clase política al más alto nivel.

La mejor prueba de este liderazgo es la capacidad que ha tenido de unificar los intereses heterogéneos y a veces dispersos de los empresarios y de gestar, en 1975, la creación del Consejo Coordinador Empresarial, la organización envolvente, cúpula de siete grandes organizaciones con voz y voto: la Asociación de Banqueros de México (ABM), La Asociación Mexicana de Instituciones de Seguros (AMIS), La Confederación de Cámaras Industriales de los Estados Unidos Mexicanos (Concamin), La Confederación de Cámaras de Comercio, Servicios y Turismo (Concanaco), la Confederación Patronal de la República Mexicana (Coparmex), el Consejo 
Mexicano de Hombres de Negocios (CMHN) y el Consejo Nacional Agropecuario (CNA); y de cinco organizaciones con voz, pero sin voto en el CCE: La Cámara Nacional de la Industria de Transformación (Canacintra), la Asociación Nacional de Tiendas de Autoservicios y Departamentales (ANTAD), el Consejo Mexicano de Comercio Exterior (COMCE), la Asociación Mexicana de Instituciones de Bolsa (AMIB), la Cámara Nacional de Comercio de la Ciudad de México (Canaco Cd de México).

El CMHN no solo creó al CCE, sino que lo dirigió en ciertos momentos cruciales entre los años 80 's y 90 's, cuando se establecieron formas inéditas de coordinación económica o de gobernanza entre sector privado y Estado ante la inestabilidad económica, social y política que vivía México en el contexto de las reformas económicas y de la nueva reinserción de México en la economía mundial. En efecto, la participación del CMHN y CCE fueron cruciales en el establecimiento de los pactos económicos tripartitos signados entre el Estado, los empresarios y los trabajadores de 1987 y hasta 1996, que por medio del control de los precios y de los salarios contuvieron la inflación (Ortega Riquelme, 2006). El CMHN también participó en la creación de la Coordinadora de Organismos Empresariales para Comercio Exterior (COECE), aliada del Estado en la negociación y firma de los tratados comerciales internacionales, entre ellos el más importante, El Tratado de Libre Comercio de América del Norte (TLCAN) (BRIZ GARIZURIETA, 2006).

Este CMHN se distingue de otras organizaciones empresariales por varias razones: no agrupa a empresas por afinidades económicas o por sectores; no se pertenece al consejo por obligación impuesta por el Estado, como fue el caso de las cámaras sectoriales desde 1936 hasta 1996; concentra a los empresarios en lo individual y de manera intergeneracional; no se puede acceder al CMHN por voluntad, como en el caso de la Confederación, sino a través de un mecanismo extremadamente selectivo; sus miembros deben poseer ciertas características muy especiales: ser presidentes del consejo de administración o tener el más alto rango en las empresas más importantes de México; ser reconocidos por su "honorabilidad, moralidad, prestigio y actuación destacada en sector empresarial"; comprometerse a no revelar asuntos tratados en el seno del con- 
sejo ni hacer declaraciones públicas en nombre del consejo. Por lo tanto, su relación con el Estado es de naturaleza distinta a la de las cámaras y confederaciones.

En el surgimiento del CMHN intervinieron factores Internacionales y nacionales. Probablemente la idea se inspiró en el modelo de la Bussiness International Roundtable de Estados Unidos, organización creada poco tiempo antes, la cual agrupa a los empresarios que dirigen las principales corporaciones de ese país. Sin embargo, la creación del CMHN guarda una relación estrecha con el contexto internacional de la época, marcado por el clímax de la Guerra Fría, la Revolución Cubana y el apoyo de México al régimen de Fidel Castro.

En lo del ámbito interno, otros elementos de discrepancia entre los empresarios y el Estado fueron provocados por la creación de los libros de texto gratuitos, únicos y obligatorios para todos los niños de educación primaria; el anuncio de la aplicación de un nuevo impuesto a patrones y asalariados del $1 \%$ el cual se destinaría al fomento de la educación media y superior; la huelga ferrocarrilera de febrero y marzo de 1959 que se consideró como resultado de agitación política, a sus líderes se les identificó como servidores de las tendencias comunistas y se acusó al Estado de "excesiva tolerancia”; la “declaración de Guaymas”, donde López Mateos (1958-1964), ante una pregunta de periodistas, declaró: "Mi gobierno es, dentro de la Constitución, de extrema izquierda"3; y la nacionalización de la industria eléctrica en 1960, ante la cual la Canacintra, distinguiéndose de las demás organizaciones empresariales, manifestó públicamente su beneplácito. A partir de estas circunstancias, los empresarios participaron en una amplia movilización social en varias regiones del país, bajo la proclama: "cristianismo sí, comunismo no" (ARRIOLA, 1997: 637).

Esta organización, denominada desde la Administración de Echeverría: Consejo Mexicano de Hombres de Negocios (CMHN) (ORTIZ RIVERA, 1998) surge de ese movimiento pendular en la representación empresarial que oscila entre la concentración y la dispersión. La élite empresarial no se siente verdaderamente representada por las cámaras empresariales ni por las confederaciones industriales,

3 Excélsior, 2 de julio de 1960, p. 19-A, citado Alcázar, 1970, p.81 
comerciales y de servicios. Las crecientes divergencias entre los empresarios y el Estado le dejan ver que las organizaciones empresariales están sujetas a la influencia, cuando no al control del Estado. Pero ¿Para qué crear una nueva organización si ya existe la Coparmex, que es de filiación voluntaria y depende totalmente de los empresarios? Tal vez haya que buscar algunas de sus explicaciones en la rivalidad de poder entre los empresarios de la ciudad de México y los de Monterrey y en la forma específica en que la Coparmex se condujo en determinadas coyunturas, entre ellas la de la administración de López Mateos, en el sentido de que no parece haber asumido una posición lo suficientemente independiente y crítica como la esperaban algunos miembros de la élite empresarial. Otra posible razón que puede estar ligada a la creación del Consejo Mexicano de Hombres de Negocios, es que, en comparación con la Coparmex, los costos de transacción representados por la coordinación y movilización del selecto grupo del CMHN son mucho menores, además de que su mismo tamaño y capacidad económica le dan una mayor capacidad de influencia.

Sin embargo, el CMHN al principio y hasta inicios de los años setenta se distinguió por su estrecha colaboración con el gobierno, al grado de invertir cuantiosos recursos para promover y mejorar la imagen que se tenía de México y sus gobernantes en el medio político y en el sector privado de Estados Unidos. Durante mucho tiempo la mayor parte de sus empresarios asociados era favorable al PRI y veía en el presidencialismo uno de los valuares de la estabilidad. Uno de sus voceros declararía ante la prensa que

la base primaria de la estabilidad política que nuestro país ha venido gozando de tiempo atrás, sin la cual hubiera sido imposible todo progreso, que ha permitido la transmisión pacífica del poder de un presidente al sucesor nueve veces (...) habiendo todos ellos terminado su período constitucional, caso único e insólito en América Latina y en muchos otros países del mundo libre, está fincada precisamente en la autoridad de la Presidencia de la República. El debilitamiento de esa autoridad representaría un daño de alcances incalculables para el futuro de nuestro país ${ }^{4}$.

4 Excélsior, 15 de junio de 1973, citado en Ortiz Rivera, 1998, p. 54. 
No tardó el conflicto; el cambio en la acción empresarial puede marcarse en 1973, durante la administración de Luis Echeverría (1970-1976), año que es parteaguas también a nivel internacional, con la crisis del petróleo como detonador, con sus consecuencias sobre las políticas nacionales e internacional.

Las conductas políticas de los empresarios serían desde entonces muy distintas a las que habían pactado con los gobiernos de la postrevolución: deciden salir de sus empresas y participar de manera abierta y directa en la política partidaria; ese es el tercer tema que trataremos en este texto.

\section{La participación de los empresarios en la transición política}

Los empresarios han sido actores importantes en la transición política de México, a lado de otros como las clases medias y algunos medios de comunicación. Lo han hecho tanto a través sus organizaciones como a título individual. El proceso se gestó desde la administración de Luis Echeverría cuyas acciones y propósitos, desde la perspectiva de los empresarios violaron el pacto tácito que se había establecido entre los empresarios y el Estado desde el período post-revolucionario: el Estado dejaba de consultar a los empresarios antes de tomar sus decisiones en materia económica. Con esto se rompía la medida de equilibrio político instaurada muchas décadas antes, la cual compensaba su falta de representación directa en el partido de estado, y con ello sentían que quedaban a merced de decisiones unilaterales que amenazaban sus intereses.

Por si fuera poco, el Estado entraba a ritmo acelerado en el espacio económico como productor directo, distribuidor y regulador; pretendía efectuar una reforma fiscal para gravar más sus intereses y creaba una Ley de Inversión Extranjera poco estimulante para atraer capitales. También les disgustaba su política "tercermundista" hacia el exterior, y la política interna, incapaz de contener la guerrilla que secuestraba y mataba a algunos de sus más prominentes representantes. Además, desde su perspectiva el Estado toleraba y hasta alentaba la lucha por la tierra para legitimarse ante una población campesina sin tierras que aumentaba, 
de ahí la expropiación de las tierras del Valle del Yaqui en Sonora, que constituyó uno de los mayores conflictos de la administración echeverrista y el inicio de la oposición de los empresarios por la vía electoral en varios municipios de Sonora ${ }^{5}$. En el campo de la cultura también surgieron tensiones, especialmente en torno a la reforma al contenido los libros de texto, los cuales fueron calificados como ideológicamente tendenciosos (VILLA LEVER, 1988 y 2010).

Para hacer frente al intervencionismo económico y social, los empresarios recurrieron a dos estrategias: una económica, a través de la fuga de capitales y la desinversión, y otra política, con la creación de Consejo Coordinador Empresarial (1975) (LUNa y TIRADO, 1992, p.86), concebido al interior del Consejo Mexicano de Hombres de Negocios para aglutinar en un frente único los intereses dispersos de los empresarios.

El gobierno de López Portillo (1976-1982) debió diseñar toda una estrategia de acercamiento para recuperar la confianza de los empresarios. Indemnizó a quienes se les expropiaron las tierras, ofreció estímulos fiscales, precios preferenciales de las empresas paraestatales y mercado protegido a los productos industriales, para lo cual decidió en 1980 que México no se incorporaría al GATT (TORRES Y FALK, 1989; POLANCO, 1990).

La expropiación de la banca tuvo una influencia directa en la politización de los empresarios (PUGA, 1986, p.391; ELIZONDO, 1993, HERNÁNDEZ, 1988a). Este hecho modificaría la hegemonía del capital financiero, crearía un vacío de poder institucional, una crisis de representación entre distintos sectores y transformaría las bases del entendimiento que se había dado entre los empresarios y el Estado desde 1925. Sin embargo, dada la heterogeneidad del empresariado, las respuestas fueron diferenciadas por instituciones y por regiones. El Consejo Coordinador Empresarial, que teóricamente debiera haber unificado las posiciones de los empresarios, no logró conseguir un consenso entre las instituciones que lo componen, sobre la postura que debía asumirse ante la expropiación de la banca.

5 Para un análisis de este proceso de politización en el noroeste de México, pueden consultarse los trabajos de Carton de Grammont, 1990; Guadarrama, 1987; y Guadarrama, 2001. 
La CONCAMIN tuvo como reacción inmediata un apoyo moderado a los banqueros y un tácito respaldo al decreto nacionalizador. La Canacintra, que había nacido a principios de los años cuarenta para representar a los que Mosk denominó "los nuevos empresarios", fue aún más cauta: no se adhirió contra el gobierno y mantuvo silencio por varios meses. Estas posturas dan testimonio de la diferenciación en las relaciones y los compromisos entre las organizaciones y el Estado, consecuencia de la heterogeneidad de ese sector y de las divergencias a su interior (PUGA, 1986, p.394).

El descubrimiento de nuevos yacimientos de petróleo y la ampliación de sus exportaciones así como el endeudamiento externo, permitieron por un tiempo la expansión del mercado, del producto y del empleo. Sin embargo México se reintrodujo a la economía mundial o ingresó a la globalización en una situación de vulnerabilidad, ya que ninguno de los pivotes en los que basaba su estrategia de desarrollo podía ser controlado desde adentro. La caída de los precios del petróleo y el aumento de las tasas de interés arrebataron al Estado toda capacidad de maniobra cuando estalló la crisis de 1982 y lo enfrentaron nuevamente a los empresarios. Esta vez el presidente optó por la expropiación de la banca (1982) y con ello marcaría un parteaguas en el cambio de un modelo de desarrollo y en el germen de la transformación del sistema político. Los empresarios se convertirían en actores centrales de la nueva economía y de la nueva política.

Las presiones que antes ejercieron desde adentro, a través de sus organizaciones o de manera informal, fueron sustituidas por acciones directas en la política partidaria y electoral, desde afuera, con el apoyo de algunas de sus organizaciones. Se convirtieron entonces en nuevos actores políticos.

La participación política de los empresarios desde la oposición no se inició desde el centro de la República ni desde las grandes empresas, aunque en varios casos hayan intervenido e incluso hayan sido detonadores importantes; se originó, como en otros movimientos sociales de la guerra de Independencia (1810-1821) y de la Revolución (1910), en algunas regiones de México; en este caso por pequeños y medianos empresarios apoyados a veces por los grandes. 
Los primeros triunfos de la oposición desde el PAN ocurrieron a nivel local en los municipios; de ahí se ampliaron a las diputaciones locales y federales, al senado, y al gobierno de varios estados, hasta a llegar a competir desde el Partido Acción Nacional (PAN) por la presidencia de la República. Gran parte de estos triunfos los obtuvieron los empresarios. Desde 1986 Manuel Clouthier, fue el primer empresario en contender a la presidencia de la república desde el PAN. Desde ese mismo partido el presidente Vicente Fox 2000-2006) fue el primero que surgió de las filas empresariales.

Los espacios de mayor activismo empresarial tuvieron lugar en las zonas más modernizadas en términos económicos, en sectores de actividad menos vinculados al modelo de sustitución de importaciones que a las exportaciones. Esto ocurrió en lugares donde los empresarios no se podían beneficiar de los apoyos y subsidios gubernamentales tanto como en otras partes; además, donde no podían recibir protección efectiva para sus productos.

En algunos estados como Chihuahua, donde la banca regional y los intereses de un variado grupo de empresarios fueron profundamente afectados, la medida desencadenó un movimiento de oposición encabezado por los empresarios, al lado de otras fuerzas políticas y sociales descontentas también por la devaluación que les impidió el acceso al mercado estadounidense. En Chihuahua los empresarios se contaron entre los pioneros que participaron en forma abierta y directa en las elecciones de 1983, cuando llevaron a uno de ellos a ocupar la presidencia municipal de ciudad Juárez, proceso que culminó una década después con el primer gobierno de alternancia en donde el gobernador panista tenía también mayoría en el congreso (BARRAZA \& BIZBERG, 1991; ALBA VEGA, 1992; AZIZ NASSIF, 1994; MIZRAHI, 1992, 1994; RIVIÈRE D’ARC, 1992).

En otros estados como Jalisco (GONZÁLEZ \& ALBA, 1989, p.111), donde la banca ya había sido absorbida por las grandes instituciones financieras nacionales, la expropiación los afectó menos en sus propiedades y en el manejo regional de los bancos; en cambio despertó entre los pequeños la esperanza de que los créditos, ahora en manos del gobierno, se canalizaran de por fin hacia ellos. Eso influiría en su posición diferenciada ante el Estado, que se limitó a la denuncia periodística y no se tradujo en accio- 
nes más decididas. No fue sino hasta 1995 cuando un conjunto de circunstancias nacionales, como la crisis financiera y sus secuelas sociales, y circunstancias regionales, como las explosiones del 22 de abril de 1992 en Guadalajara, el asesinado del Cardenal Posadas, la violencia ligada al narcotráfico y la injerencia económica del ejecutivo estatal en negocios antes reservados al sector privado, como la producción inmobiliaria, llevaron a un nutrido grupo de empresarios medianos y pequeños a adherirse a una corriente muy amplia que en 1995 llevó al triunfo del PAN en el gobierno y casi todas las diputaciones y alcaldías.

En Nuevo León, y sobre todo en su capital Monterrey, sede de la clase empresarial más independiente y poderosa del país ${ }^{6}$, las discrepancias y los conflictos con el Estado han persistido a lo largo del tiempo. Los empresarios se mantuvieron siempre al margen de la política directa sin por eso dejar de influir en ella. Cuando por fin entraron a la contienda abierta, lo hicieron de manera pragmática; al interior de las mismas familias unos miembros militan en el partido oficial y otros en la oposición. Desde los años sesenta empezaron a ganar algunas alcaldías de la zona metropolitana de Monterrey consideradas las de mayores ingresos y más industrializadas del país; además, altos funcionarios de los grupos económicos contendieron por la alcaldía de Monterrey en 1976 en elecciones cuyos resultados fueron muy impugnados; otros compitieron por el gobierno del Estado en 1979. A pesar de la gran influencia de los empresarios regiomontanos sobre la ciudad de Monterrey, y de que no han sido objeto de hostilidad por parte de los trabajadores, quienes recibieron de aquellos más beneficios sociales y económicos de los que entregaba el Estado en otras partes, no fueron los primeros en conseguir grandes triunfos electorales en favor del PAN. Sin embargo, a finales de los noventa un notable empresario del Partido Acción Nacional (PAN) alcanzó la gubernatura del estado.

6 Existe una abundante bibliografía sobre el proceso de formación económica y social de los empresarios de Nuevo León, pero mucho menos sobre sus relaciones políticas. Algunos de los trabajos a los que se puede recurrir para los dos temas, son los siguientes: Cerutti, 1983 y 2000; Flores Torres, Olvera y González, 1988; Mauro, 1964; Nuncio, 1982; Pozas, 2002; Revel-Mouroz, 1976; Vellinga, 1979; Vizcaya Canales, 1971. 
Las peculiaridades de cada región fueron decisivas. Las zonas de mayor efervescencia política de los empresarios en rebeldía contaban con un componente regionalista y de oposición al centro más alto que en el resto del país, como ha ocurrido también con el proceso electoral del PAN, fenómenos que están interrelacionados. En los estados donde el peso de las clases medias era fuerte y el PAN podía contar con mayores bases, tradición y arraigo, se facilitó la participación y el triunfo de los empresarios politizados.

Varios líderes empresariales habían intentado incidir en la política y habían procurado conseguir precandidaturas para ocupar cargos públicos desde el PRI y solo cuando vieron bloqueado su acceso buscaron otras alternativas.

Los empresarios en la oposición panista tienen varias procedencias. Unos fueron directores de nivel medio y superior de grandes corporaciones nacionales, principalmente en el norte del país; otros contaban con sus propias empresas. Casi todos accedieron a la educación superior, tanto en instituciones públicas como sobre todo en universidades privadas, en donde destacan el Tecnológico de Monterrey y la Universidad Iberoamericana. Sus estudios generalmente tienen vínculos estrechos con las áreas económico-administrativas.

Con algunas excepciones constituidas por empresarios que han sido líderes pioneros o antiguos militantes del PAN, la mayor parte son relativamente jóvenes y ellos nutrieron la llamada corriente neopanista. Casi todos contaban con experiencia en cargos de responsabilidad y representación en los organismos empresariales, algunos en asociaciones agrícolas, otros en las cámaras industriales, más aún en las de comercio, pero sobre todo en los Centros Patronales (después llamados Centros Empresariales) pertenecientes a la Coparmex, que se convirtieron en los principales lugares de toma de conciencia y politización.

Del reclamo de la libertad en lo económico, los empresarios más distantes del Estado, que se localizaban principalmente en torno a la Coparmex (TIRADO, 1984; BUENDÍA LAREDO, 1989) y la Concanaco, pasaron a la lucha política por la ampliación de la democracia. La mayor parte de los gobiernos de oposición se incubaron en esta tendencia empresarial crítica al Estado. Fueron ellos quienes transgredieron la norma de no participar y salieron de sus 
empresas al encuentro de la política. Sin embargo, los empresarios panistas no fueron los únicos en entrar a la política. Muy pronto aparecieron muchos otros empresarios que engrosaron las filas del PRI. Los perfiles socioprofesionales y las plataformas electorales de los empresarios priístas y panistas, al menos a nivel local y estatal y en el proyecto económico, fueron muy cercanos, al grado que los candidatos podrían ser intercambiables entre ambos partidos.

Las conductas políticas de los empresarios son diferenciadas y dependen de las singularidades territoriales, de las áreas de actividad económica, del capital económico y político que poseen, de la generación a la que pertenecen, del medio en el que se socializaron, de las historias específicas que han vivido. Todo eso puede distinguir y matizar sus acciones, sin embargo pueden señalarse ciertos rasgos comunes al observar sus conductas en estos años recientes. Pasaron de una reacción defensiva a una acción propositiva. Dos ejemplos institucionales son la creación del Consejo Coordinador empresarial (CCE, 1975) para el primer caso, al que ya nos hemos referido, y la Coordinadora de Organizaciones Empresariales para el Comercio Exterior (COECE, 1991), para el segundo. Aunque esta última organización sobrerepresentó los intereses de los grandes empresarios y subrepresentó los de los pequeños (Puga, 1994; Alba Vega, 1996), se constituyó sin duda en la mayor instancia de cabildeo que ha creado el sector privado para participar al lado del Estado, en este caso, en las negociaciones del Tratado de Libre Comercio de América del Norte (TLCAN).

Desde el salinismo, con la profundización de la liberalización de la economía y la reforma del Estado, las organizaciones empresariales más independientes del Estado, como la Coparmex, replegaron su acción política y tendieron a neutralizar, equilibrar y desideologizar sus posiciones. Gran parte de los empresarios panistas y priístas fueron salinistas. En varios de sus consejos han tratado de mantener un equilibrio entre el número de miembros afiliados al PRI y al PAN. También declararon que no vetarían a ningún partido político y ofrecieron a sus agremiados las diversas plataformas electorales.

Si la agresividad antiestatista, antipriísta y anticentralista de los empresarios disminuyeron, como también la movilización social 
y el nivel de politización, no ocurrió lo mismo con su interés por participar directamente en la política a título individual. Ha sido tan grande ese interés, que a veces han transgredido las posiciones de las organizaciones que representan y se involucran en política partidaria en apoyo a algún precandidato, como ocurrió con Eduardo Bours, presidente del Consejo Coordinador Empresarial, quien se ofreció a incorporarse a la campaña del precandidato prí́sta Francisco Labastida. Es cada vez mayor el número de miembros del sector privado que compiten, ganan elecciones y ocupan cargos como gobernadores, senadores, diputados federales y locales, ya sin contar a todos los presidentes municipales de pequeños pueblos, donde también hay casos de empresarios del PRD, y grandes ciudades, donde alternan empresarios prí́stas y panistas. A todos estos cargos de elección popular, habría que agregar una larga lista de hombres de empresa que participan en la función pública por designación, por ejemplo, como secretarios de finanzas, de fomento económico y de otras secretarías de los gobiernos estatales y municipales.

El interés de los empresarios en la política está orientado hacia dos grandes valores: la libertad y la democracia. Desde su perspectiva, pretenden conseguirlos defendiendo desde la política al mercado, para disminuir la incertidumbre derivada del voluntarismo y los virajes sexenales. De ahí que los más grandes hayan promovido y respaldado la apertura económica y la firma del TLCAN ${ }^{7}$, ya que aparte de ser éste un desafío y una oportunidad en lo económico, es un candado político ante la tentación del intervencionismo.

Las cámaras empresariales se han transformado también a lo largo del tiempo. Originalmente fueron privadas y desde 1908, por iniciativa gubernamental, se convirtieron en "cuasi-públicas"; Además, a partir de 1936 los empresarios debieron afiliarse obligatoriamente y pagar una cuota. Al lado de las cámaras y de las organizaciones patronales privadas, desde los años ochenta surgió otro tipo de asociaciones privadas paralelas. Algunas de ellas fueron más ágiles que las cámaras para adaptarse a los nuevos requerimientos de la economía; otras, muy poderosas, como la Asociación Nacional

7 Tratado de Libre Comercio de América del Norte - TLC, es conocido también por TLCAN o como NAFTA - North American Free Trade Agreement. 
de Tiendas de Autoservicio y Departamentales (ANCTAD), aparecieron como una alternativa de la que podía valerse el Estado para negociar directamente ciertas políticas, mientras la administración de Salinas de Gortari tuvo diferencias con la Concanaco. En el marco de una economía cerrada y sobreregulada, estas instituciones tuvieron varias funciones de gestoría; desde ellas se negociaron y obtuvieron precios, permisos de importación y exportación, concesiones, exenciones de impuestos, subsidios y créditos, protección arancelaria y muchas otras políticas públicas en materia económica. La apertura de la economía afectó por lo tanto la naturaleza, la estructura y el funcionamiento de estas organizaciones; varias de sus funciones reales se hicieron redundantes y obsoletas, por lo que las instituciones han estado bajo el imperativo de reorientarse hacia la promoción y el servicio a sus socios si quieren conservarlos. Muchos de sus presidentes y directores se resistieron a suprimir la cláusula de afiliación obligatoria porque consideraron que perderían las cuotas de las que vivían las instituciones. Además, en el contexto de la inestabilidad económica y política, tampoco desde el lado del Estado se veía la conveniencia de urgir por los cambios. La Nueva Ley de Cámaras Empresariales y sus Confederaciones de 1997 libró a los empresarios de la afiliación obligatoria por la que lucharon desde los años ochenta, pero no de inscribirse en el Sistema de Información Empresarial Mexicano (SIEM) por motivos de información estadística, ni de pagar una cuota a las cámaras para el manejo de este sistema (Arriola, 1997).

Distinguiéndose de las organizaciones empresariales de gran parte de los países latinoamericanos, durante la crisis de los años ochenta y hasta los noventa, favorecieron la integración intraclase, y los acuerdos interclases, con otros sectores sociales. De ahí que haya sido posible establecer acciones concertadas, alianzas, compromisos y pactos generales para la estabilización, acordados con el Estado y otros actores como las organizaciones sindicales oficiales.

Un momento importante que reflejó las diversas posiciones políticas de las organizaciones empresariales fueron las elecciones presidenciales de 2006. Conviene examinar cuales fueron sus preferencias y sus conductas. 


\section{Los empresarios y las elecciones presidenciales de 2006}

Las elecciones presidenciales de 2006 en México constituyen un analizador importante para observar el vínculo entre los empresarios y la política. Esas elecciones estuvieron enmarcadas en un conjunto de factores externos e internos que influyeron sobre ellas. Entre los elementos externos están las características de la relación económica de México con Estados Unidos y del gobierno del presidente Bush, así como el arribo de partidos de izquierda a los gobiernos de varios países de América Latina.

La relación económica y social de México con Estados Unidos se ha ido densificando desde hace muchas décadas y es la tela de fondo que sirve de escenario para las relaciones políticas. Algunas de las principales variables de la presencia e influencia de Estados Unidos sobre México se expresan en las siguientes variables: dos terceras partes de la inversión extranjera directa en México provienen de su vecino del norte; la presencia de cerca de 3,220 plantas maquiladoras de exportación que emplean a casi 1200,000 personas, lo que equivale a casi un tercio de la fuerza de trabajo ocupada en el sector industrial; el flujo de turistas que llegan a México, de los cuales dos terceras partes provienen de Estados Unidos; los emigrantes mexicanos que viven en Estados Unidos, los cuales ascendían a un millón en 1970 y sobrepasaban los 10 millones en 2010 (cada año entran más de 500 mil mexicanos sin papeles a estados Unidos); las remesas de esos migrantes, que alcanzaron la cifra record anual en 2007 con el envío de 26 mil millones de dólares; el cuantioso pero incuantificable valor de las mercancías introducidas de contrabando, de acuerdo con una tradición casi centenaria; la fuga de capitales, la cual pasó de 1976 a 1995 de menos de cuatro mil millones de dólares a más de 40 mil millones; los depósitos privados de mexicanos radicados en este país en cuentas bancarias en Estados Unidos, los cuales entre 1975 y 1995 ascendieron a la cifra de 71,364 millones de dólares; el tráfico ilegal de narcóticos que por la violencia e inseguridad que engendra se ha convertido en uno de los problemas más importantes de México y de la agenda entre este país y Estados 
Unidos; la deuda externa de México, de la que bancos de Estados Unidos han sido los principales acreedores, la cual pasó en la administración de Echeverría de 4 mil millones a 20 mil millones de dólares, y durante la de López Portillo de 20 mil millones a 100 mil millones de dólares; la fuerte liga comercial de México con EEUU, que representa el $88.5 \%$ del comercio total de México.

Las visiones y posiciones de los partidos y de los candidatos presidenciales de México ante estos grandes temas de la agenda binacional influyen sin duda en los apoyos y las demandas de la población en general y de los empresarios en particular. Por otra parte está la influencia ideológico política del progresivo arribo de partidos de izquierda a varios gobiernos de países de América Latina, con sus grandes diferencias, como las que existen entre Néstor Kirchner en Argentina, Evo Morales en Bolivia, Lula en Brasil, Michelle Bachelet en Chile, Tabaré Vázquez en Uruguay y Hugo Chávez en Venezuela. Estos gobiernos estuvieron presentes también como tela fondo en contexto de elecciones en México e incidieron de manera ambivalente; fueron utilizados como apoyos/rechazos a candidatos. En este mismo contexto, en México como en otros 10 países de América Latina en que hubo elecciones presidenciales en 2006, existieron posibilidades concretas de que un partido de izquierda llegara al poder. Por tal motivo, es importante asentar que en caso de que llegaran, la convivencia entre ellos y los empresarios sería inevitable. ¿Cómo sería en el caso de México?

Tal como se desarrollaron los procesos electorales para las elecciones presidenciales de 2006 en México, la figura de Roberto Madrazo, el candidato del PRI se desvaneció por su mala imagen, lo que llevó a que hubiera solo dos fuerzas con posibilidades reales de ganar: la del centro-derecha encabezada por Felipe Calderón, el candidato del PAN, y la del centro-izquierda representada por Andrés Manuel López Obrador, el candidato del Partido de la Revolución Democrática (PRD). Ante ellas se presentaron dos escenarios: si triunfaba Calderón, habría uno con más similitudes que diferencias respecto al inmediato sexenio anterior del panista Vicente Fox. Si ganaba Andrés Manuel López Obrador se estaba frente a otro con mayor incertidumbre. ¿Cuál fue la posición y la acción de los empresarios en estos escenarios? 
Aunque organismos empresariales intentaron mantener posiciones neutrales y se mostraron al principio respetuosos de acatar los resultados, es indudable que los empresarios tuvieron preferencias muy definidas en torno al proceso y que actuaron para hacerlas valer. Lo difícil es saber con precisión cuales son, porque no existe empresariado homogéneo, sino diversidad de posiciones. Podríamos plantear como hipótesis las siguientes propuestas:

I - La posición de los grandes empresarios. La mayor parte de ellos, que nacieron y crecieron bajo el modelo de industrialización por sustitución de importaciones, apoyaron durante mucho tiempo al PRI. Durante los períodos de mayor intervencionismo del Estado hicieron fuertes críticas y pugnaron por un cambio político orientado a ampliar los cauces democráticos, y por un cambio económico dirigido a liberalización de economía. Después de la crisis de la deuda, establecieron coaliciones con una corriente tecnocrática de esos empresarios y fueron muy cercanos a los presidentes Carlos Salinas de Gortari y Ernesto Zedillo, y apoyaron la transformación del modelo económico orientado a la apertura comercial, la desregulación, la privatización de las empresas paraestatales y la reprivatización de la banca, de las cuales fueron los principales beneficiarios.

La mayoría de los grandes empresarios no apoyó de manera importante a Vicente FOX durante su candidatura en las elecciones de 2000. Sin embargo, desde que este candidato triunfó y el PRI se convirtió en partido de oposición, esos empresarios se acercan al gobierno del PAN, aunque muchos tenían esperanza que volviera a ganar aquel PRI de los tecnócratas. Sin embargo, los grandes empresarios quedaron insatisfechos del desempeño de la administración de Fox en cuanto a su capacidad de negociación política y de construir acuerdos para hacer pasar las grandes reformas que les interesaban: la energética, la hacendaria y la laboral; aunque reconocieron que durante su mandato la real división de poderes dificultó capacidad de acción del presidente. Cuando se definieron las candidaturas de Roberto Madrazo por el PRI y Felipe Calderón por el PAN, se presentó un momento de definiciones para ellos. Los que simpatizaban con el PAN reafirmaron sus convicciones; los proclives al PRI, al ver que su candidato fue perdiendo posición en las preferencias electorales, se fueron desplazándose hacia PAN. Son muy pocos, pero existen, 
los grandes empresarios que tenían relación con Manuel Andrés López Obrador. La rehabilitación del Centro Histórico de la ciudad de México puso a prueba las posibilidades de diálogo y participación de los empresarios ligados a proyectos inmobiliarios, turísticos, de hotelería, restaurantes y al comercio tradicional. Sin embargo, el discurso de López Obrador, y su negativa a dialogar con los grandes empresarios, en especial con los banqueros, lo alejó de élites empresariales, las que se asustaron ante lo que podría ocurrir si ese candidato llegase a ganar, y así decidieron actuar en la campaña electoral transgrediendo ley electoral.

El CCE al final de la campaña presidencial, violando la legislación electoral, orientó su apoyo hacia el candidato Felipe Calderón a través de dos spots. En el primero se presenta el cierre de puertas de varios negocios pequeños y una voz en off que dice:

A lo largo de los últimos diez años, el país ha creado los mecanismos e instituciones necesarias para que cada día surjan más pequeños empresarios que puedan hacerse de un patrimonio y sacar adelante a sus hijos, ese es el gran camino para México: iCrecer! Porque al crecer uno, crecemos todos. Apostarle a algo distinto es retroceder.

Inmediatamente después, aparece una bicicleta cayéndose en una calle ante un vendaval Otra vez el narrador en off afirma: "iDefendamos lo que hemos logrado! Consejo Coordinador Empresarial." La escena del vendaval puede interpretarse como los vientos violentos del cambio, que terminan por derrumbar la bicicleta. "Éste es un claro mensaje a inducir el voto por la continuidad, y de los tres candidatos más importantes, el candidato de la continuidad era Felipe Calderón” (MUÑOZ COTA, 2010).

En el segundo spot se presenta a un niño con un billete de 20 pesos que se ganó después de hacer veinte "mandados" o favores. A manera de entrevista con el narrador, el spot continúa:

"Voz de Hombre: ¿Son tuyos esos veinte pesos?

Niño: Sí, es mi billete, veinte mandados, veinte pesos.

Voz Hombre: ¿Y si te digo que una devaluación y que tus veinte pesos ya sólo valen diez?

Niño: ¿Me estás mintiendo, verdad? iAquí dice: veinte pesos! Estás bromeando (el niño se ríe) 
Voz en off: ¿No te parece maravilloso que nuestros hijos ya no entiendan lo que nosotros sufrimos tantas veces? Esto es producto de diez años de estabilidad económica. Apostarle a algo distinto es retroceder. Defendamos lo que hemos logrado. Consejo Coordinador Empresarial"

Nuevamente "este corte comercial hace un llamado explícito a la continuidad. Las devaluaciones, son quizá, uno de los elementos más importantes y traumáticos en la conciencia colectiva del mexicano después de que en el país sucedieron depreciaciones abruptas de la moneda nacional (...) Durante el sexenio de Vicente Fox no hubo una devaluación tan fuerte como en los gobiernos anteriores. Por lo tanto, este spot llamaba a votar por la continuidad de la política económica del gobierno foxista" (MUÑOZ COTA, 2010).

Ese factor sería decisivo para explicar la derrota de Andrés Manuel López Obrador (AMLO), al lado de los aciertos de la campaña de Calderón, sus alianzas con el magisterio disidente a través de la profesora Elba Esther

Gordillo, así como los errores de la campaña de López Obrador, como el hecho de no sentarse a dialogar en la primera mesa de los candidatos, no dialogar con los empresarios, radicalizar su discurso y asustar a una parte de clases medias.

II - Los pequeños y medianos empresarios en las elecciones de 2006 estuvieron muy divididos entre los tres partidos principales. La Canacintra, que pretende agrupar a los pequeños y medianos empresarios, mantuvo históricamente una posición cercana a los gobiernos del PRI; en algunos casos esta organización sirvió de plataforma para que sus directivos alcanzaran puestos públicos de representación en los gobiernos priístas. Sin embargo, desde que el PRI se convirtió en oposición, algunos de sus dirigentes simpatizaron con el PRD y después se convirtieron en candidatos (Yeidckol Polevsky) de ese partido y en promotores del acercamiento de los empresarios de la Canacintra con el PRD. Estos empresarios fueron sensibles al mensaje de López Obrador que hablaba de la "necesidad de recuperar y reactivar el mercado interno". En algunos momentos, tuvieron confrontaciones con CCE. Por lo tanto estos empresarios de la Canacintra estuvieron divididos entre PRD y el PRI, aunque sin duda había también simpatizantes del PAN. 
La Coparmex hizo un esfuerzo por mantenerse imparcial como organización hacia sus afiliados. En ella hay simpatizantes y han salido candidatos para los tres principales partidos. Sin embargo, es indudable que desde una perspectiva histórica ha sido un semillero de líderes panistas en los ámbitos local, regional y nacional.

III - Los micro empresarios y la población de la economía informal frente a las elecciones y los candidatos. Existe una categoría de micro-empresarios de economía informal en la que podemos ubicar a los comerciantes ambulantes, los "tianguistas"8, los trabajadores por cuenta propia, los no asalariados y los que podemos llamar "asalariados truncos", como son los trabajadores de los empresarios del sector informal, ya que la relación salarial no es plena, puesto que no cuentan con ninguna forma de protección social. En todos estos sectores se dio fenómeno parecido al de los más grandes empresarios, pero en otra dirección. Históricamente estuvieron muy ligados al PRI, pero en los espacios en que el PRD ha ganado las elecciones locales, se han pasado a este partido, alentados muchas veces por los funcionarios perredistas, que antes fueron también priístas, o simplemente por conveniencia política, para poder seguir ejerciendo sus actividades sin hostigamiento gubernamental.

Si durante el modelo de industrialización por sustituciones los actores sociales estaban corporativizados a través de sus organizaciones sindicales adscritas al partido oficial (PRI), las que daban garantías de estabilidad en el empleo y defensa de los salarios, durante el modelo abierto al exterior estas corporaciones, por ejemplo la de los obreros, perdieron su funcionalidad al no poder ofrecer ni empleos seguros ni salarios remuneradores. Por lo tanto la población trabajadora prefirió laborar por cuenta propia para ganar flexibilidad e ingresos.

Esa flexibilidad también se expresa en la dimensión política. Son la base social de relevo (vendedores ambulantes, tianguistas, taxistas) ante el debilitamiento del asalariado de empresa y del

8 El tianguis es el nombre náhuatl y prehispánico de los mercados; por extensión así se llama los mercados populares "informales", también llamados mercados sobre ruedas, o "tiraderos", aunque puede haber diferencias entre ellos, que durante algunos días de la semana funcionan al aire libre. 
corporativismo. Son actores pragmáticos que definen sus lealtades y sus acciones en función de sus necesidades inmediatas, entre las cuales el espacio físico de trabajo es primordial. En gran parte de eso deriva su facilidad de movilización social y política en apoyo o en rechazo de alguna causa.

Los vendedores ambulantes son actores sociales en búsqueda de representación. Sus líderes son plenamente conscientes de la necesidad de ganarse la legitimidad de sus bases. Necesitan estar cerca de los actores, pulsar y dar respuestas satisfactorias a sus necesidades económicas, sociales, políticas.

El cambio de partidos políticos en el gobierno de la ciudad de México a partir del triunfo de Cuauhtémoc Cárdenas en el PRD para el gobierno de la ciudad en 1997, propició un cambio muy rápido de partido por parte de los ambulantes, los cuales eran priístas y desde entonces al menos la mitad son perredistas. El cambio se facilitó también porque algunas autoridades del PRI que tenían los vínculos con las organizaciones de ambulantes se cambiaron con todo y sus bases al PRD. Muchos líderes con sus bases cambiaron sin resistencia; otros se enfrentaron y perdieron, otros más permanecieron fieles a su partido de origen. Las organizaciones cambiaron de forma también: pasaron de la concentración a la fragmentación del liderazgo por razones políticas de los partidos (para debilitarlos) y por deseos de emancipación de los delegados de los líderes que aspiraban a encabezar liderazgos; como resultado perdieron poder. Por otra parte, la afiliación (informal), por ser clientelar y no corporativa (sindical), es mucho más volátil, porque depende de personas concretas y podría cambiar si cambiase el gobierno. Además, no se puede controlar el voto, aunque sí se les puede presionar a participar en marchas y movilizaciones, como lo han hecho otros partidos políticos también.

\section{El impacto de la crisis mundial contemporánea en México.}

Por su alto grado de integración a la economía de Estados Unidos, México fue uno de los países más afectados de América Latina por la crisis mundial que se inició como una crisis financiera y 
se convirtió en una crisis de empleo de alcance mundial, la cual tuvo como epicentro a aquel país (Boyer, 2010). En 2009 la caída del PIB en México fue de - 6.8\%, la peor desde 1932 (77 años) cuando cayó 14\%. En 2009 se perdieron en México 181, 271 empleos formales, mientras cada año se necesitan crear 1 millón 300 mil puestos de trabajo para ocupar solo a los que deberían ingresar al mercado de trabajo cada año.

Esa crisis llegó en el peor momento, cuando la pirámide demográfica se ensancha más rápido en su parte media (los adultos en edad de trabajar) y cuando el flujo de jóvenes en búsqueda del primer empleo es más vigoroso (SAMANIEGO, 2010, p.68).

El número de pobres en América Latina subió de 180 millones en 2008 a 189 millones de personas en 2009 , los que representan $34.1 \%$ de la población total. Mientras, el universo de personas en indigencia aumentó de 71 a 76 millones, que significan el 13.7 por ciento de la población. El porcentaje de mexicanos en situación de pobreza creció al 38.8 por ciento de la población total, es decir, afecta a 41 millones 252 mil personas. Esto representa un crecimiento de 4 millones 253 mil personas en un año, prácticamente la mitad de los 9 millones de toda la región.

\section{Gráfica 1 - Tasas anuales de crecimiento}

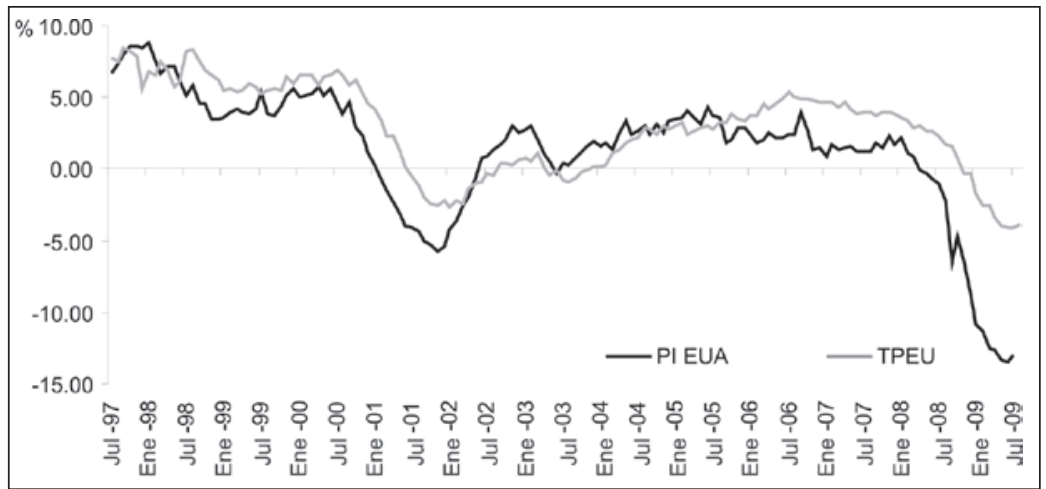

Fuente: IMSS. Consulta dinámica de información. www.imss.gob.mx, 17 de agosto de 2010 Comunicado. Coordinación de Comunicación Social, 7 de septiembre de 2009, Núm. 226 Nota: PI EUA = Producción Industrial en Estados Unidos TPEU $=$ Trabajadores Permanentes y Eventuales Urbanos asegurados en el Instituto Mexicano del Seguro Social 
La alta integración de la economía mexicana a la estadounidense, la cual se observa claramente al comparar en la Grafica 1 la tasa anual de crecimiento de la producción industrial en Estados Unidos con la del crecimiento de los trabajadores (permanentes y eventuales) en México, tuvo efectos muy negativos desde la crisis. La inversión extranjera, que entre 1999 y 2009 alcanzó la cifra acumulada de 227,017.60 millones de dólares, de los cuales dos terceras partes provienen de Estados Unidos, en 2008 fue de 23, 170 millones de dólares y para 2009 había descendido a 11,417 millones de dólares, es decir, cayó más de 50\%.

Un buen indicador para medir el impacto de esta crisis en México es el empleo formal a través del registro del personal asegurado, permanente y eventual, en el Instituto Mexicano del Seguro Social (IMSS). A partir de ese registro podemos extraer del Cuadro 1 algunas conclusiones:

Los grupos de actividad económica más afectados por la crisis, en orden decreciente en cuanto al comportamiento del empleo en su momento de mayor caída, entre diciembre de 2006 y agosto de 2009, son el industrial, el cual se contrajo -10.2 por ciento; después, el de Transporte y Comunicaciones, que creció solo 0.7 por ciento en ese período; luego la industria de la Construcción, el cual aumentó únicamente 2 por ciento; el comercio que aumentó 4.6 por ciento y el sector agrícola, la ganadería, la pesca, la industria extractiva y la energía eléctrica que crecieron en conjunto 4.8 por ciento; y finalmente, los menos afectados fueron los Servicios Sociales, el cual creció 6.8 por ciento; y sobre todo los Servicios a Empresas, que aumentaron 12.3 por ciento.

Dentro del sector más perjudicado, el industrial, las ramas más golpeadas por la crisis iniciada en 2007 podemos clasificarlas en tres grupos:

1 - Las que agrupan a las industrias maquiladoras y a las más vinculadas a las exportaciones y a la economía de Estados Unidos, como son la industria de la confección (-24.5), el equipo de transporte (-19.5), es decir, la industria automotriz y de partes para ese sector; la maquinaria y el equipo eléctrico y electrónico (-18.3); la 
industria de las bebidas (cerveza, tequila) (-5.6); los minerales no metálicos (cemento para exportación e industria de la construcción nacional) $(-10)$.

Un sector industrial especialmente sensible ha sido el automotriz, que desde mediados de los años ochenta y sobre todo a partir del TLCAN, ha orientado sus ventas al extranjero. Tanto las grandes plantas estadounidenses, Ford, Chrysler y General Motors, como las asiáticas, Honda y Toyota, y las europeas, Volkswagen y Nissan / Renault, fueron muy afectadas. Además, la caída de la demanda descendió en cascada a los proveedores medianos y pequeños, gran parte de los cuales son también inversionistas extranjeros.

2 - Las ramas industriales que producen para el mercado interno, pero que son muy sensible a la competencia exterior: muebles y accesorios (-17.2), el sector textil (-12.6), la industria y los productos de madera (-12.3), las industrias del cuero y el calzado (-10.6), la industria del papel (-2).

3 - Las ramas industriales afectadas de manera indirecta, por sus vínculos con otras: productos metálicos (-7.5), Industria editorial (-4.5), hule y plástico (-3-6), industrias metálicas básicas (ligadas a la construcción) (-1).

Existe un grupo de sectores industriales que si bien no sufrieron un fuerte menoscabo en cuanto al personal ocupado durante este período, sí tuvieron un crecimiento mínimo, por lo que pueden considerarse en muy cerca del estancamiento desde el punto de vista laboral. Tales son: la industria química (3.4), la fabricación de alimentos (1.2) y la de maquinaria y equipo no eléctrico (0.5).

Las ramas industriales menos perjudicadas por la crisis son la de productos del tabaco (4.7) y muy especialmente la refinación de petróleo (14.6). 
Cuadro 1

Trabajadores permanentes y eventuales urbanos afiliados al IMSS por grupo de actividad aconómica

\begin{tabular}{|c|c|c|c|c|c|c|c|c|c|}
\hline \multirow[b]{2}{*}{ Grupo de Actovidad Económica } & \multirow[b]{2}{*}{ 31-Ago-2009 } & \multirow[b]{2}{*}{ 31-Jul-2009 } & \multirow[b]{2}{*}{ 31-Ago-2008 } & \multirow[b]{2}{*}{ 31-Dic-2008 } & \multirow[b]{2}{*}{ 31-Dio-2006 } & \multicolumn{4}{|c|}{ Variación porcentual"/ } \\
\hline & & & & & & 31.Jul-09 & 31-A90-08 & 31-Dis:08 & 31-Dic-06 \\
\hline INDUSTRIAS DE TRANSFORMACION & $\begin{array}{l}, 467,307 \\
\end{array}$ & $3,444,868$ & $3,838,724$ & $\begin{array}{l}, 617,187 \\
\end{array}$ & $3,3,859,246$ & 0.65 & -9.68 & -4.14 & -10.16 \\
\hline Productos de tabaco & 4,598 & 4,884 & 4,726 & 4,522 & 4,393 & -5.86 & .2 .71 & 1.68 & 4.67 \\
\hline Otras incustrias manufactureras & 145,998 & 147,841 & 167.905 & 159.391 & 165,087 & -1.25 & -13.06 & -8.40 & -11.56 \\
\hline Industria textal & 101,562 & 101,268 & 109.844 & 98,046 & 118,148 & 0.29 & -7.54 & 3.59 & .12 .56 \\
\hline Industria química & 221,761 & 200,009 & 227,261 & 219.917 & 214,560 & 0.52 & -2.42 & 0.84 & 3.36 \\
\hline Maquinaria y equipo no electrico & 102,086 & 101,917 & 112.215 & 105226 & 101,570 & 0.17 & -9.03 & -2.98 & 0.51 \\
\hline Productos metalicos & 295,271 & 295,434 & 333.840 & 312.822 & 319,103 & -0.06 & -11.55 & -5.61 & $-7,47$ \\
\hline Industrias metálicas básicas & 69.670 & 68,953 & 75,560 & 70,704 & 70,358 & 1.04 & .7 .80 & -1.46 & -0.98 \\
\hline Industria y productos de madera & 35,944 & 36,436 & 39,636 & 37,117 & 40,970 & -1.49 & -9.31 & $-3,16$ & -12.27 \\
\hline Industria del papel & 83.621 & 83.511 & 89,810 & 85,701 & 85,443 & 0.13 & -6.89 & -243 & -2.13 \\
\hline Equipo de transportación & 373,262 & 363,116 & 452.214 & 411,165 & 453,477 & 2.79 & -17.46 & .9 .22 & .19 .46 \\
\hline Elaboración de bebidas & 128,103 & 128.567 & 134,501 & 131,332 & 135.680 & -0.36 & -4.76 & -2.46 & -5.58 \\
\hline Productos minerales no metálicos & 120,682 & 120.972 & 135,796 & 127.047 & 134,288 & -0.24 & -11.13 & -5.01 & -10.13 \\
\hline Fabricación de alimentos & 521,327 & 520,395 & 525,436 & 528,031 & 515,130 & 0.18 & -0.78 & -1.27 & 1.20 \\
\hline Productos de hule y plastico & 228,083 & 227,105 & 245,722 & 223.942 & 236,659 & 0.43 & .7 .18 & 1.85 & -3.62 \\
\hline Maquinaria y equipo eléctrico & 436,596 & 427,107 & 516,528 & 475,155 & 534,190 & 2.22 & -15.47 & -8.12 & -18.27 \\
\hline Industria editorial y de impresion & 137,508 & 137,835 & 148,730 & 141.758 & 143,951 & -0.24 & -7.55 & -300 & -4.48 \\
\hline Muebles y accesorios & 77.233 & 76,637 & 87.672 & 82,354 & 93,288 & 0.78 & -11.91 & -6.22 & -17.21 \\
\hline Refinación de petróleo & 7,422 & 7,405 & 7,093 & 6,895 & 6.477 & 0.23 & 4.64 & 7.64 & 14.59 \\
\hline Prendas de vestir & 277,792 & 277,587 & 320,064 & 297.627 & 357,983 & 0.07 & -13.21 & -6.66 & -24.51 \\
\hline Industria del cuero y calzado & 98.788 & 97,239 & 104,143 & 98,435 & 110,491 & 1.59 & -5.14 & 0.36 & -10.59 \\
\hline INDUSTRIA DE CONSTRUCCION & $1,121,296$ & $1,120,259$ & $1,246,646$ & $1,099,429$ & $1,098,988$ & 0.09 & -10.05 & 1.99 & 2.03 \\
\hline Edificaciones y obras de ingenieria & 921,986 & 921,084 & $1,029,174$ & 6.5 .817 & 915,111 & 0.10 & -10.41 & 2.92 & 0.75 \\
\hline Trabajos de contratistas & 199,310 & 199,205 & 217,472 & 2003.612 & 183.877 & 0.05 & -8.35 & -2.11 & 8.39 \\
\hline COMERCIO & $2,845,787$ & $2,839,322$ & $2,873,400$ & $2,924,109$ & $2,720,085$ & 0.23 & -0.96 & -2.68 & 4.62 \\
\hline Equipo de transportación y refacciones & 172,468 & 171.988 & 183.221 & 179,128 & 178,483 & 0.28 & -5.87 & -3.72 & -3.37 \\
\hline Maquinaria y equipo & 231,715 & 209.886 & 234,055 & 237.278 & 208.255 & 0.80 & -1.00 & -2.34 & 11.27 \\
\hline Materias primas y materiales & 378,589 & 378,314 & 387,303 & 360.851 & 362,448 & 0.07 & .2 .25 & -0.59 & 4.45 \\
\hline Alimentos, bebidas y tabaco & 586,198 & 584.572 & 587,906 & 587,028 & 549,746 & 0.28 & .0 .29 & -0.14 & 6.63 \\
\hline Gases, combustibles y lubricantes & 192,345 & 192.273 & 193,747 & 196.270 & 188.856 & 0.04 & -0.72 & -2.00 & 1.85 \\
\hline Prendas de vestir $y$ articulos personales & 492,163 & 492,155 & 498,783 & 504,079 & 434,480 & 0.00 & -1.33 & -2.36 & 1.59 \\
\hline Inmuebles y articulos diversos & 112,575 & 112,772 & 112,072 & 113,070 & 106,423 & -0.17 & 0.45 & -0.44 & 5.78 \\
\hline Articulos para el hogar & 136,095 & 137,264 & 142,252 & 147.816 & 143,624 & -0.85 & -4.33 & .7 .93 & -8.43 \\
\hline Tiendas autoservicio y departamentales & 543,639 & 540.098 & 534,056 & 578.589 & 492,770 & 0.66 & 1.79 & -6.04 & 10.32 \\
\hline TRANSPORTE Y COMUNICACIONES & 738,611 & 741,064 & 771.550 & 765.065 & 733,586 & -0.33 & -4.27 & 3.46 & 0.68 \\
\hline Transporte por agua & 29,620 & 30,246 & 30.901 & 31,881 & 25,277 & -2.07 & -4.15 & -7.09 & 17.18 \\
\hline Transporte aereo & 29,049 & 29,361 & 32295 & 30,695 & 32,158 & -1.06 & -10.05 & -5.36 & -9.67 \\
\hline Servicios relacionados con transporte & 171,384 & 172,740 & 184,426 & 180,007 & 171,059 & -0.78 & -7.07 & -4.79 & 0.19 \\
\hline Transporte terrestre & 398,720 & 399,023 & 414,914 & 411,355 & 402,107 & -0.08 & -3.90 & -3.07 & -0.84 \\
\hline Comunicaciones & 82,994 & 82,947 & 84.522 & 84,758 & 80,352 & 0.06 & -1.81 & -2.08 & 3.29 \\
\hline Servicios conexos al transporte & 28.244 & 26.747 & 24,492 & 26.369 & 22.633 & 0.36 & 9.60 & 1.80 & 18.51 \\
\hline SERVICIOS PARA EMPRESAS & $3,327,722$ & $3,324,512$ & $3,392,224$ & $3,349,936$ & $2,962,508$ & 0.10 & -1.90 & -0.66 & 12.33 \\
\hline Servicios de alojamiento temporal & 272,694 & 280,702 & 289.596 & 296.299 & 271,291 & -2.85 & -5.84 & -7.97 & 0.52 \\
\hline Servicios profesionales y técnicos & $1,646,324$ & $1.635,078$ & $1,673,417$ & $1,637,390$ & $1,365,428$ & 0.69 & -1.62 & 0.55 & 20.57 \\
\hline Servicios financieros y de seguros & 232,549 & 231,904 & 230.225 & 232.407 & 200,132 & 0.28 & 1.01 & 0.06 & 16.20 \\
\hline Servicios de alquiler, excep inmuebles & 39,238 & 39,789 & 41,238 & 40,755 & 36,357 & -1.38 & -4.85 & -3.72 & 7.92 \\
\hline Servicios personales. hogar y diversos & 436,784 & 434.810 & 446,784 & 438.369 & 416.284 & 0.45 & -2.24 & -0.36 & 4.92 \\
\hline Servicios colaterales a instit financieras & 61,521 & 60,903 & 56,558 & 58,185 & 54,327 & 1.01 & 8.78 & 5.73 & 13.24 \\
\hline Preparación de alimentos y bebidas & 455,973 & 455,746 & 472.601 & 406,462 & 453,911 & 0.05 & -3.52 & -2.25 & 0.45 \\
\hline Servicios recreativos y esparcimiento & 150,363 & 153,263 & 148,092 & 146.878 & 133,869 & -1.89 & 1.53 & 2.37 & 12.32 \\
\hline Servicios relacionados con inmuebles & 32.276 & 32,317 & 33.711 & 33,191 & 30,909 & -0.13 & -4.26 & -2.76 & 4.42 \\
\hline SERVICIOS SOCIALES & $1,728,734$ & $1,714,401$ & $1,672,444$ & $1,696,712$ & $1,618,551$ & 0.84 & 3.37 & 1.89 & 6.81 \\
\hline Servicios enseñanza e investigación & 508,675 & 490,109 & 494,362 & 502,498 & 476,508 & 3.79 & 2.80 & 1.23 & 6.75 \\
\hline Agrupacior & 52.599 & 53,455 & 48,87 & 49,844 & 46,170 & -1.60 & 7.62 & 5.53 & 13.92 \\
\hline Organizaciones internacionales & 2,457 & 2,441 & 2.285 & 2,322 & 2,163 & 0.66 & 7.53 & 5.81 & 13.59 \\
\hline Servicios medicos & 200,489 & 200,103 & 198,153 & 199,303 & 184,353 & 0.19 & 1.18 & 0.60 & 8.75 \\
\hline Servicios de administración pública & 964,514 & 968,293 & 928,767 & 942.745 & 909,357 & -0.39 & 3.85 & 231 & 6.07 \\
\hline OTROS GRUPOS & 609,473 & 623,565 & 591,539 & 610,114 & 581,737 & .2 .26 & 3.03 & -0.11 & 4.77 \\
\hline Extrac.de petról.crudo y gas nat. & 22.813 & 22.553 & 18.629 & 19,420 & 7,585 & 1.15 & 22.46 & 17.47 & 200.76 \\
\hline Extrac,y benef. de min. metalicos & 38,375 & 37,840 & 38,769 & 35,989 & 29,669 & 1.41 & -1.02 & 6.63 & 29.34 \\
\hline Silvicultura & 2804 & 2.840 & 3,172 & 3,065 & 2935 & -1.27 & -11.60 & -8.52 & .4 .46 \\
\hline Explotación de s. & 2.036 & 2.073 & 1,882 & 1,933 & 1.845 & -1.78 & 8.18 & 5.33 & 10.35 \\
\hline Captación y sum, de agua potable & 51,331 & 51,246 & 47,685 & 49,144 & 44,453 & 0.17 & 7.65 & 4.45 & 15.47 \\
\hline Ganaderia & 110,477 & 110,158 & 112.320 & 110,262 & 110,743 & 0.29 & -1.64 & 0.19 & .0 .24 \\
\hline Energia eléctrica & 121,033 & 122,736 & 120,724 & 122.582 & 117,309 & -1.39 & 0.26 & -1.26 & 3.17 \\
\hline Agricultura & 199,085 & 214,333 & 183,444 & 208.726 & 209,944 & .7 .11 & 8.53 & -4.62 & -5.17 \\
\hline Carbón mineral & 37,890 & 37,782 & 38,902 & 37,361 & 36,129 & 0.13 & -2.76 & 1.26 & 4.71 \\
\hline Caza & 83 & 83 & 96 & 108 & 149 & 0.00 & -13.54 & -23.15 & -44.30 \\
\hline Pesca & 23.606 & 21,921 & 25.916 & 21.524 & 20,976 & 7.69 & -8.91 & 9.67 & 12.54 \\
\hline TOTAL & $13.838,930$ & $13,808,021$ & $14,386,527$ & $14,062,552$ & $13,574,701$ & 0.22 & -3.81 & -1.59 & 1.95 \\
\hline
\end{tabular}

" De la cifra al 31 de acosto de 2009 respecto a cada uno de los periodos del cuadro.

Si se observa la tendencia de la ocupación entre los trabajadores permanentes y los eventuales urbanos registrados en el IMSS, se percibe un incremento en la proporción de los trabajadores eventuales urbanos en relación con el total, la cual pasó el 10.5 por ciento en enero de 2007 a 11.5 por ciento en agosto de 2009; esta tendencia, que como lo muestra la gráfica 2 , es anterior a la presente recesión y significa que hay un deterioro en la calidad del trabajo. 
Gráfica 2

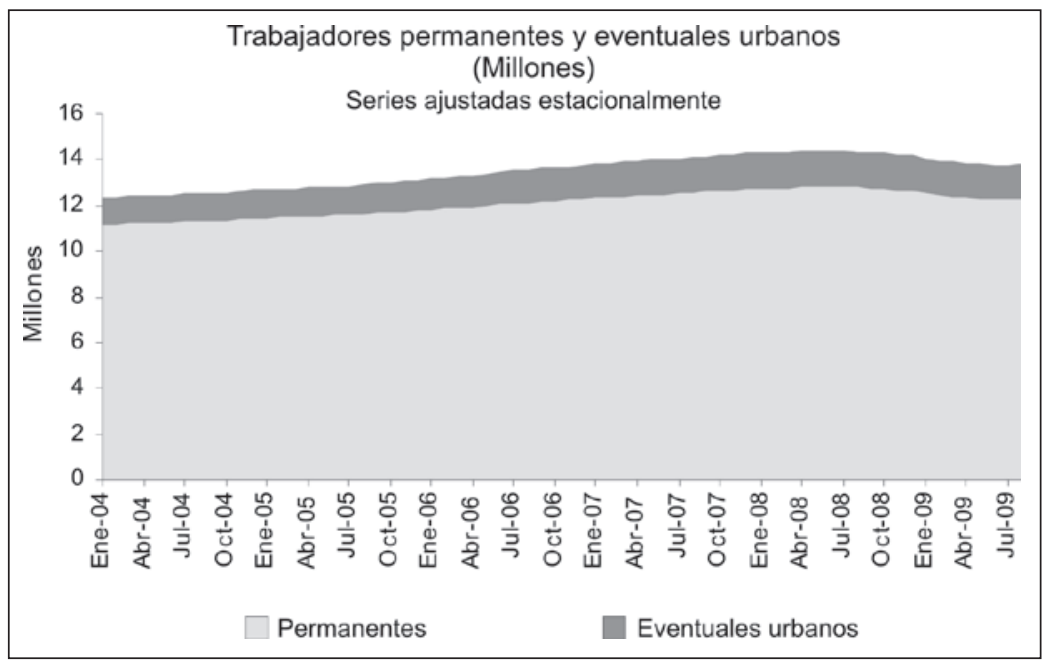

Fuente: IMSS. Consulta dinámica de información. www.imss.gob.mx, 17 de agosto de 2010 Comunicado. Coordinación de Comunicación Social, 7 de septiembre de 2009, Núm. 226

En una visión de conjunto podemos decir que la industria maquiladora de exportación, una de las industrias más afectadas, es una forma de producción dividida en la que la parte intensiva en capital se realiza en Estados Unidos y la parte intensiva en trabajo en México. Surgió desde los años sesenta con ventajas potenciales para los dos países. En México pretendía paliar los efectos negativos que tendría el fin del "Programa Bracero" (1942-64) por el que salían miles de mexicanos cada año para trabajar en los puestos vacantes que dejaban los estadounidenses que partían a la Segunda Guerra Mundial. En Estados Unidos era una manera de hacer frente, abatiendo los costos de producción, a la creciente competencia que infligían los países de nueva industrialización del sudeste asiático. En 2007 esta industria contaba con 2,819 plantas y empleaba a 1, 201,449 personas (Noviembre 06). La mayor parte de los empleos industriales que se perdieron en México como consecuencia de la crisis provienen de estas empresas maquiladoras.

El turismo ha sido otro de los sectores que cayeron más. En 2008 el turismo de internación, que excluye a los turistas fronterizos y a los que viajan en cruceros, alcanzó la cifra de 11, 927,000 
personas, de las cuales el 67 por ciento provienen de EEUU; de enero a octubre de 2009 las divisas internacionales por el turismo cayeron 17 por ciento.

Las inversiones inmobiliarias en el sector turístico, tanto la construcción de hoteles y condominios de playa como departamentos en playa y en las ciudades, bajaron también como consecuencia de la crisis en Estados Unidos y en España, los principales inversionistas en este sector. La caída se reflejó en el descenso de la ocupación en el sector y en los proveedores de los hoteles

Las remesas que envían los más de 10 millones de mexicanos que viven en Estados Unidos han sido también afectadas por la crisis. La cifra record de remesas desde que se tienen registros tuvo lugar en 2007, con el envío de 26,068.7 millones de dólares; para 2008 descendieron a 25,137.37 millones dólares (equivalentes al 3 por ciento del PIB, es decir, mayores que la Inversión Extranjera Directa); para 2009 bajaron a 21,181 millones de dólares, $15.7 \%$ por ciento menos que en 2008. En algunos casos no generalizables, la pérdida de empleos de los mexicanos en Estados Unidos ha llevado al reenvío de remesas de México hacia aquel país. La caída de las remesas significa menos recursos para los sitios de destino, menos consumo y empleo, que en realidad son los lugares de origen de los emigrantes. Sin embargo, no ha habido una repatriación masiva de mexicanos, aunque las deportaciones de migrantes sin papeles han aumentado considerablemente (en 2009 ascendieron a cerca de 500 mil) y se ha endurecido y militarizado la frontera, por lo que cada vez es más peligrosa e insegura para todos los mexicanos y latinoamericanos que intentan cruzarla.

La crisis económica coincide con el recrudecimiento del narcotráfico, su combate y la violencia concurrente. Desde 2006 hasta 2010 ha habido más de 22 mil 743 víctimas. En los últimos tres años, de 2007 a 2010 ha habido más de 15.000 muertes, pese al despliegue de más de 50.000 militares; eso significa que en México ha habido más muertos ligados al narcotráfico que en varias de las guerras recientes en Medio Oriente.

Además, la pandemia de la Fiebre A (H1N1) que se inició en abril de 2009 se empalmó con la crisis económica y acrecentó su impacto negativo en la economía. Aunque no existe un balance 
completo, diversos indicadores muestran cifras muy negativas. Un informe de CNN Expansión, indica que los negocios tuvieron una pérdida del $80 \%$ en sus ventas durante los días en que las autoridades prohibieron asistir a lugares públicos. El sector turístico fue muy afectado; las cancelaciones de reservaciones en los hoteles del Caribe llegaron hasta un 70\%. Según la Cámara Nacional de Aerotransportes de México, las aerolíneas reportaron un 40\% en la tasa de cancelaciones, a mayo de 2009. Mexicana de Aviación, que atravesaba por una severa crisis económica en agosto de 2010 y que estaba a punto de la quiebra, argumentó que una de las razones de su crisis deriva, entre otros factores, de la caída de la demanda provocada por la pandemia de 2009. Además, muchos países bloquearon los productos provenientes de México ante la posibilidad de contagio. Por otra parte, el gobierno debió realizar gastos adicionales para contrarrestar la pandemia: ofreció ayudas de hasta 1,200 millones de dólares como incentivo ante las pérdidas en ventas. Para hacer frente a este problema, el Banco Interamericano de Desarrollo aprobaría una línea de crédito por un monto de 3.000 millones de dólares para evitar la propagación del virus, los cuales representan el triple del total de la cartera del BID en México (http://www.elobservadoreconomico.com/articulo/935, 15 de agosto de 2010 .

Sin embargo el problema del empleo en México es muy anterior a la presente crisis y es de naturaleza estructural. Ante la incapacidad del mercado de trabajo formal para absorber a la población joven, esta ha recurrido a tres válvulas de escape. La primera es el ingreso a la que por falta de un mejor término podríamos llamar "economía informal", que ha desplazado al empleo formal como principal fuente de trabajo en México. La segunda es la emigración laboral a Estados Unidos, que en los últimos años se calcula en 500 mil trabajadores anuales, una de las más altas del mundo y que es otra de las grandes diferencias de la situación de México respecto al resto de países latinoamericanos. Estas salidas ante la falta de trabajo, y la falta de protección económica ante el desempleo explicaron hasta antes de esta crisis el atípicamente "bajo" desempleo abierto, por lo que esas tasas bajas no pueden compararse con las de otros países para evaluar la salud del mercado de trabajo (SAMANIEGO, 
2010, p.68). La tercera es la expansión de actividades consideradas no solo como ilegales, sino como criminales, entre las que predomina el narcotráfico, el cual se ha convertido en los últimos años en uno de los problemas más graves del país.

Sin embargo las dos primeras válvulas parecen estarse reduciendo en la presente crisis: el mercado de trabajo informal por la contracción de la masa salarial y por la fuerte competencia de los nuevos contingentes que trabajadores por cuenta propia; la emigración laboral por la falta de opciones laborales en Estados Unidos y por la caída de las remesas. Ante este panorama, han aparecido nuevos fenómenos, como la retención por más tiempo de la población en el campo, los llamados jóvenes ni-ni, un sector de la población que ni estudia ni trabaja. Ante esa falta de alternativas ocupacionales y ante la precarización de los puestos de trabajo aún en la economía formal, la criminalidad se ha convertido en una importante fuente de ingresos (Samaniego, 2010: 67-68).

Esta crisis tuvo efectos negativos para todos los sectores de actividad económica en todo el país, sin embargo sus resultados son diferenciados en cuanto a su severidad e intensidad. Sin duda son los sectores más pobres de la población los más afectados. Hemos visto cuantos mexicanos se convirtieron por la crisis en pobres extremos. También los sectores asalariados fueron muy golpeados. Por su parte, los empresarios han sido afectados de diversos modos. Desde el proceso de apertura económica, mucho antes de la crisis, algunos grandes empresarios mexicanos habían vendido sus negocios. Por ejemplo, los industriales que fabrican tequila, cerveza y acero. Lo mismo ocurrió con algunas grandes cadenas comerciales, como Aurrerá, quien vendió a Wal Mart. Casi todos los bancos pasaron a la banca extranjera: Bancomer a BBV, Banamex a City Bank, Serfín a Santander.

Sin embargo, al mismo tiempo muchas grandes empresas se han internacionalizado, por ejemplo Telmex, América Móvil, Televisa, Cemex, Imsa, Gruma, Bimbo, y hay más mexicanos en la listas de los ricos mundiales que figuran en las revistas de negocios, por ejemplo Carlos Slim, que encabezó la lista en el último año. Algunos de estos empresarios acrecentaron sus fortunas durante las crisis de los años ochenta y noventa a través del sistema financiero. 
El impacto de la crisis en el ámbito espacial es también diferenciado. Si tomamos en cuenta como indicador el personal asegurado en el IMSS, a partir del Cuadro 2, podemos dividir en cuatro grupos a los estados más afectados por la crisis en cuanto al volumen del personal despedido en la economía formal:

1 - Los del norte de México que hacen frontera con Estados Unidos: Baja California, Chihuahua, Coahuila, Nuevo, León, Sonora y Tamaulipas, que son también los espacios donde se concentra la mayor parte de las industrias maquiladoras de exportación.

2 - La ciudad de México y el Estado de México, donde se encuentra gran parte de las inversiones extranjeras y de las grandes empresas mexicanas.

3 - Los estados que cuentan con plantas de la industria automotriz, además de las que están en los estados de la frontera norte: Aguascalientes, Jalisco, (afectado también por el turismo) el Estado de México, Morelos, Puebla, San Luis Potosí.

4 - Algunos de los estados con mayor presencia de inversiones en turismo: Quintana Roo, Baja California Sur, Guerrero y Yucatán.

En contraparte, de acuerdo con las mismas fuentes, a los estados de la república que perdieron menos personal ocupado podemos dividirlos en dos grupos:

1 - Los más pequeños, con menor demografía y mayor proporción de población rural (Colima, Durango, Hidalgo, Tlaxcala).

2 - Los estados que cuentan con menos personas aseguradas, es decir menos empresas y personas en la economía formal. Estos estados han recibido también los menores montos de inversión extranjera. Son los estados menos urbanizados y con los menores índices de desarrollo humano; los más pobres: Campeche. Chiapas, Michoacán, Zacatecas. Veracruz forma parte de estos estados menos afectados por la crisis en razón de la importancia que tiene el petróleo en su economía y por los precios de este combustible en esa coyuntura. 


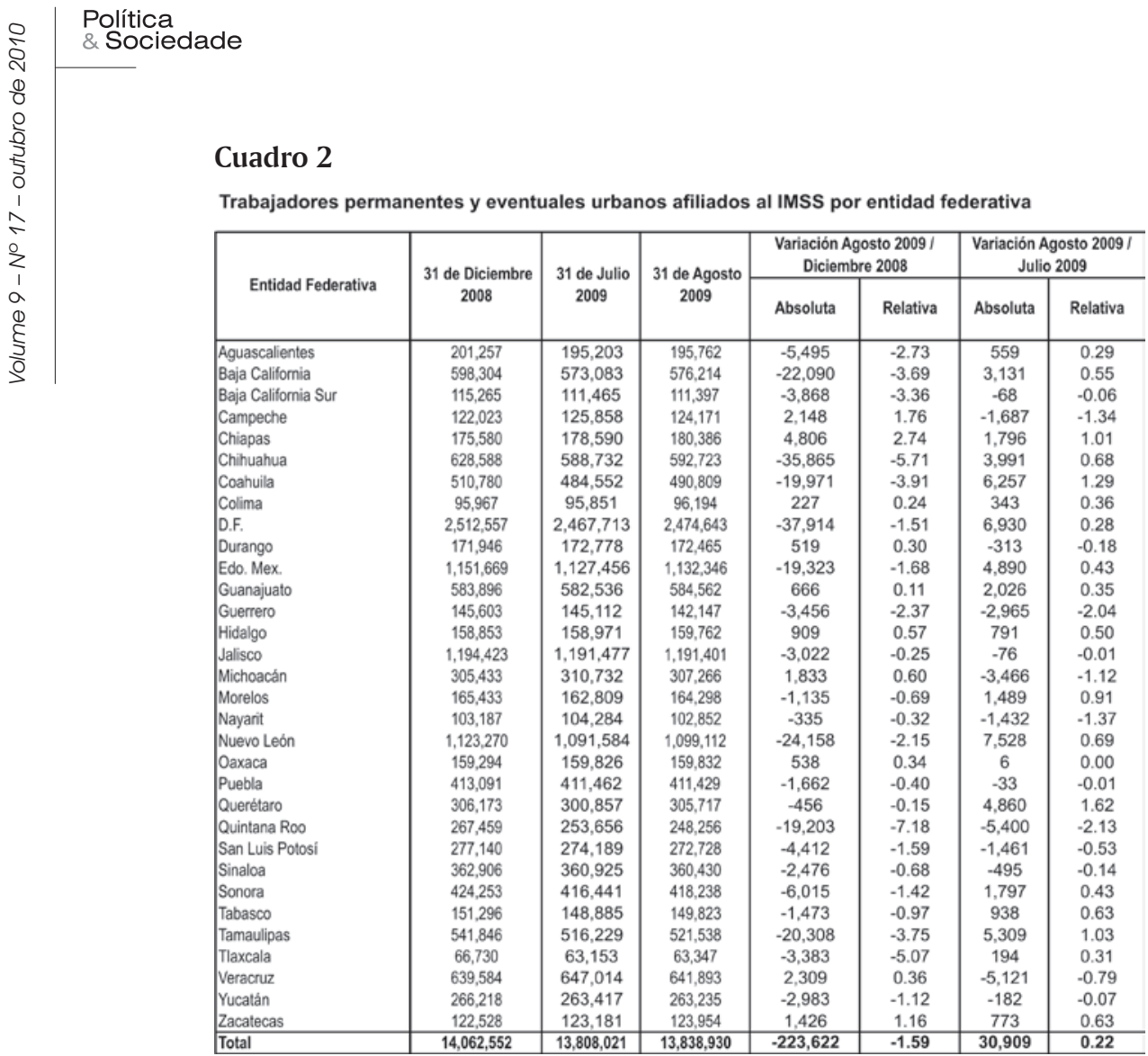

Fuente: IMSS. Consulta dinámica de información. www.imss.gob.mx, 17 de agosto de 2010 Comunicado. Coordinación de Comunicación Social, 7 de septiembre de 2009, Núm. 226

\section{Conclusiones}

Las relaciones de los empresarios con el Estado en México se distinguen de las de otros países latinoamericanos por la influencia que ha tenido sobre ellas el origen revolucionario del Estado mexicano y por la historia específica que ha sido moldeada por factores geoeconómicos, demográficos, sociales y políticos. A diferencia de otras revoluciones sociales, como la rusa, la china o la cubana, la mexicana no solo respetó su existencia, sino facilitó su nacimiento y desarrollo. El Estado Mexicano, al surgir no de revolución conservadora sido de amplios movimientos políticos y sociales, configuró un sistema político con ciertas singularidades en relación con los empresarios. Les abrió las puertas de la economía 
y de los negocios y los protegió para que crecieran y se desarrollaran como clase social. A cambio, se estableció un pacto tácito: los empresarios permanecerían alejados de política. Sin embargo, eso no impidió que muchos políticos se hicieran empresarios (por ejemplo, Aarón Sáenz, Abelardo L. Rodríguez, Miguel Alemán Valdés); fenómeno inverso a finales del siglo XX y principios del $\mathrm{XXI}$, cuando de las empresas llegaron a la política (entre muchos otros Miguel Alemán Velasco, Manuel Clouthier, Vicente Fox). Si el Estado marcó ciertos límites a la acción de los empresarios pretendiendo con ello proteger los intereses de otros sectores sociales, en la práctica no logró orientar un desarrollo que propiciase una sociedad razonablemente igualitaria e incluyente a largo plazo. En consecuencia, tanto por el origen del sistema político como por los resultados del modelo de desarrollo, los empresarios se ubicaron en una situación ambivalente. Por una parte eran visualizados como un factor de modernización para el país; por la otra, algunos actores sociales que participaron en la revolución los empujaron fuera de los espacios de representación del nuevo orden político, donde otros sectores como los militares, los obreros y los campesinos sí tenían un lugar. El espacio de acción de los empresarios se limitó al campo económico, aunque de manera limitada; tendrían derecho a ser consultados por el gobierno en materia de política económica, para eso se crearían las cámaras y confederaciones de industriales y comerciantes. La falta de representación política directa a través de los partidos se supliría con formas de relación informales y personalizadas a través de las cuales expresaban sus demandas y defendían sus intereses al más alto nivel. Sin embargo, en los aspectos sociales y políticos, cuando aparecieron conflictos que no pudieron resolverse por esos mecanismos, los empresarios prefirieron crear sus propias instituciones, distintas también a las de otros países latinoamericanos, entre las que destacan la Coparmex (1929), el Consejo Mexicano de Hombres de Negocios (1962) y el Consejo Coordinador Empresarial (1975).

Si al principio los empresarios fueron débiles y frágiles como categoría social, al grado que el Estado debió protegerlos para que pudieran desarrollarse, con el tiempo crecieron, se diversificaron y fortalecieron tanto, principalmente en la metrópoli nacional y en las 
dos metrópolis regionales, que los más grandes de ellos destacaron por sus fortunas en el ámbito mundial.

Los empresarios decidieron entrar a la política partidaria cuando el Estado, ante el agotamiento del modelo de Industrialización por Sustitución de Importaciones, determinó intervenir de manera creciente y directa en la economía para dinamizarlo. Sintieron que con ello se atentaba contra sus intereses y convinieron en propiciar la competencia electoral y en participar directamente como nuevos actores políticos. El quiebre del modelo, con la crisis de la deuda de 1982 y la fuga de capitales que llevó al gobierno a expropiar la banca fueron el detonador. A partir de entonces los empresarios se constituyeron en los actores centrales -y los más grandes de ellos, en los beneficiarios principales- del nuevo modelo enmarcado en la era de la globalización, en sustitución del Estado como agente de desarrollo, al tiempo que ensancharon su participación en la política. Este "gran acuerdo" (CONCHEIRO, 1996) y fuerte convergencia entre las políticas públicas en materia económica y los intereses de los empresarios, en especial los mejor colocados en el marco de la economía globalizada, no están exentos de divergencias internas dentro del mismo sector empresarial respecto a la manera de afrontar la crisis y en torno al proceso de apertura económica y de alternancia política. Estas discrepancias derivan de su gran heterogeneidad como actores económicos y de su singularidad como sujetos sociales y políticos.

La crisis de la deuda de 1982 y las consecuencias que tuvo en la economía y la sociedad llegaron a la política: erosionó la legitimidad que el Estado había conseguido en los sectores populares y las clases medias a través de la movilidad social y económica durante varias décadas. Las urnas fueron importantes por primera vez desde la crisis de los años ochenta, y los empresarios las empezaron a usar para hacer frente al intervensionismo, también acosado por los acreedores externos y por una fracción de la clase política tecnocrática.

La inestabilidad económica repercutió en la estabilidad política que había conseguido el Estado posrevolucionario. Los empresarios dejaron de admirar a ésta y al presidencialismo y empezaron a hacer política de otro modo. Los empresarios pequeños 
y medianos que eran más independientes, o los ubicados en las zonas más afectadas por las expropiaciones de tierras y bancarias dictadas desde el centro, decidieron participar en la competencia política tanto desde el PAN como desde el PRI. Con sus recursos económicos, humanos y organizativos lograron transitar con éxito desde los niveles locales y regionales hasta el nacional. Nunca como ahora habían ostentado tanto poder económico y político al mismo tiempo. Al frente de un empresario, el PAN consiguió llegar a la presidencia de la república en 2000 , después de un dominio del PRI de 70 años ininterrumpidos. Sin embargo las elecciones presidenciales de 2006 fueron especiales. Estas elecciones estuvieron influidas por un conjunto de factores internacionales y nacionales. Entre los primeros, por el referente del gobierno republicano de George Bush en Estados Unidos y por el arribo de muchos gobiernos de izquierda en los países de América Latina.

Del mismo modo que en 10 países de América Latina en que habría elecciones ese año, existieron posibilidades reales de que un partido de izquierda triunfara en las elecciones. Ante este hecho, los empresarios asumieron distintas posiciones, dependiendo de su tamaño y actividad económica, de factores regionales, económicos, ideológicos y políticos.

La mayor parte de los grandes empresarios, quienes nacieron y crecieron bajo el modelo ISI, apoyaron durante mucho tiempo al PRI y en los períodos de mayor intervencionismo del Estado hicieron fuertes críticas al gobierno y pugnaron por un cambio político orientado a ampliar los cauces democráticos, y por un cambio económico dirigido a la liberalización de la economía. Después de la crisis de la deuda, establecieron coaliciones con la corriente tecnocrática de la clase política priísta y fueron muy cercanos a las presidencias de Salinas de Gortari y Zedillo, a las que apoyaron en la transformación del modelo de desarrollo volcado al exterior con la participación clave del CMHN (BRIZ GARIZURIETA, 2008). La mayoría de ellos no apoyó de manera importante al candidato panista Vicente Fox en las elecciones de 2000, pero cuando el PRI se convirtió en partido de oposición aumentó el número de los que se acercaron al PAN. Quedaron insatisfechos del desempeño de esta administración en cuanto a su capacidad de negociación política y 
de construir acuerdos para hacer pasar las grandes reformas que les interesaban (energética y hacendaria, y en otro nivel menos importante para ellos, la del trabajo).

Cuando el candidato del PRI perdió sus posibilidades de ganar según las preferencias electorales previas a la elección de 2006 y ante la polarización PAN-PRD, desplazaron sus preferencias hacia el PAN. Pocos grandes empresarios tuvieron relación y simpatía con el candidato del PRD. La radicalización discursiva de López Obrador contra el Fobaproa ${ }^{9}$ y los banqueros lo alejó aún más de las élites empresariales, las que, violando la legislación, participaron activamente en su contra en una campaña de mensajes televisivos bien orquestada que influyó de manera decisiva en los resultados de las elecciones (MUÑOZ COTA, 2009).

Los pequeños y medianos empresarios estuvieron muy divididos políticamente entre los tres principales partidos. Los agrupados en la Canacintra siempre mantuvieron una relación simbiótica y corporativizada con los gobiernos del PRI (SHADLEN, 2004); varios de sus dirigentes pasaron de esa cámara a ocupar cargos políticos. Desde que el PRI se convirtió en oposición, aparecieron sectores empresariales al más alto nivel del organismo camaral que simpatizaron con el PRD, y después se convirtieron en candidatos de ese partido y en promotores del acercamiento de los empresarios de la Canacintra con este partido.

La Coparmex hizo un esfuerzo por mantenerse imparcial como organización, y entre sus afiliados hubo simpatizantes y candidatos para los tres principales partidos. Sin embargo, es indudable que desde una perspectiva histórica ha sido un semillero de líderes panistas en los ámbitos local, regional y nacional.

9 El Fondo Bancario de Protección al Ahorro (Fobaproa) fue creado por el gobierno mexicano en 1990 a partir de las crisis de los años ochenta como un fondo de contingencia para enfrentar posibles problemas financieros, sobre todo la eventual insolvencia de los bancos por el incumplimiento de los deudores o el retiro masivo de depósitos. En 1998 se transformó en el Instituto para la Protección al Ahorro Bancario (IPAB). El Fobaproa cubriría las carteras vencidas de los deudores de la banca, muchos de los cuales no eran pequeños deudores sino grandes empresarios. El tema de los beneficiarios de este financiamiento a largo plazo con recursos fiscales de todos los mexicanos se convirtió en uno de los temas más polémicos de la política mexicana. 
Los microempresarios y la población de la economía informal frente a las elecciones y los candidatos manifestaron diversas conductas. Los micro-empresarios de la economía informal, los "tianguistas", los trabajadores por cuenta propia, los no asalariados y los que podemos llamar "asalariados truncos", como son los trabajadores de los empresarios del sector informal, ya que la relación salarial no es plena, se dio un fenómeno parecido al de los más grandes empresarios, pero en otra dirección. Históricamente estuvieron muy ligados al PRI, pero en los espacios en que el PRD ha ganado las elecciones locales, se han pasado a este partido alentados muchas veces por los funcionarios perredistas, que antes fueron también priístas. Las corporaciones que agrupan a estos actores perdieron funcionalidad al no poder ofrecer ni empleos seguros ni salarios remuneradores a partir de la crisis de 1982 y del cambio de modelo. La población prefirió trabajar por cuenta propia para ganar flexibilidad e ingresos; esa flexibilidad también se expresa en la dimensión política. Son la base social de relevo (ambulantes, tianguistas, taxistas) ante el debilitamiento del asalariado de empresa y del corporativismo. Son actores pragmáticos que definen sus lealtades y sus acciones en función de sus necesidades inmediatas, entre las cuales el espacio físico de trabajo es primordial. En gran parte de eso deriva su facilidad de movilización social y política en apoyo o en rechazo de algo o de alguien. El cambio de partidos políticos en el gobierno del Distrito Federal propició un cambio muy rápido de partido por parte de los vendedores ambulantes, los cuales eran priístas y ahora al menos la mitad son perredistas. El cambio se facilitó en parte porque las autoridades del PRI, quienes tenían los vínculos y el control de las organizaciones de ambulantes, se cambiaron con todo y sus bases al PRD. La afiliación (informal), por ser clientelar y no corporativa (sindical), es mucho más volátil porque depende de personas concretas y podría cambiar si cambiase el gobierno. En las elecciones de 2006 gran parte de los microempresarios de la economía informal fueron proclives al PRD.

El gobierno del presidente Calderón (2006-2011) debió enfrentar no solo un fuerte problema de legitimidad, sino también una grave crisis económica e inseguridad incontrolada. La presente crisis tuvo un mayor impacto negativo en México (la caída 
del PIB en 2009 fue de -6.8 por ciento) que en los demás países latinoamericanos por su fuerte integración económica y social con Estados Unidos. Esa crisis provocó un aumento de la pobreza en América Latina; los pobres aumentaron de 180 millones en 2008 a 189 millones en 2009; de esos nueve millones, casi la mitad correspondió a México. Todas las formas de integración económica entre Estados Unidos y México se revirtieron con consecuencias negativas para este país. Entre 2008 y 2009 la inversión extranjera cayó un 50 por ciento. El sector de actividad económica más afectado fue el industrial, que se contrajo -10.2 por ciento entre enero de 2007 y agosto de 2009; después siguieron el de Transporte y Comunicaciones, que creció solo 0.7 por ciento en ese período; luego la industria de la Construcción, el cual aumentó únicamente 2 por ciento. Los menos afectados en cuanto al empleo fueron el comercio (4.6 por ciento), el sector agrícola, la ganadería, la pesca, la industria extractiva y la energía eléctrica ( 4.8 por ciento) y especialmente los Servicios Sociales (6.8 por ciento) y los Servicios a Empresas, que aumentaron 12.3 por ciento.

Dentro del sector industrial, las ramas más golpeadas por la crisis iniciada en 2007 fueron: 1.- Las que agrupan a las industrias maquiladoras y a las más vinculadas a las exportaciones y a la economía de Estados Unidos: la confección (-24.5), el equipo de transporte (automotriz) (-19.5), la maquinaria y el equipo eléctrico y electrónico (-18.3); la industria de las bebidas (cerveza, tequila) (-5.6); los minerales no metálicos (cemento) (-10). 2.- Las ramas industriales que producen para el mercado interno, pero que son muy sensibles a la competencia exterior: muebles y accesorios $(-17.2)$, el sector textil (-12.6), la industria y los productos de madera (-12.3), las industrias del cuero y el calzado (-10.6), la industria del papel (-2). 3.- Las ramas industriales afectadas de manera indirecta, por sus vínculos con otras: productos metálicos (-7.5), Industria editorial (-4.5), hule y plástico (-3-6), industrias metálicas básicas (ligadas a la construcción) $(-1)$.

El turismo ha sido otro de los sectores que más cayeron. Las inversiones inmobiliarias en el sector turístico, tanto la construcción de hoteles y condominios de playa como departamentos en playa y en las ciudades, bajaron también como consecuencia de la crisis 
en Estados Unidos y en España, los principales inversionistas en este sector. La caída se reflejó en el descenso de la ocupación en el sector y en los proveedores de los hoteles.

Las remesas que envían los más de 10 millones de mexicanos que viven en Estados Unidos han sido también afectadas por la crisis, las cuales cayeron de 26,068.7 millones de dólares en 2007 a 21,181 millones de dólares en 2009 .

La crisis económica coincide en México con el recrudecimiento del narcotráfico y con el aumento de la violencia y la inseguridad; y también se empalmó con el brote de la pandemia de la Fiebre A (H1N1) que se inició en abril de 2009, la cual caló más en la economía por los efectos que tuvo en el turismo, la hotelería, el transporte aéreo y el gasto adicional del gobierno para contener su propagación.

La crisis tuvo efectos diferenciados y los sectores pobres de la población fueron los más afectados; desde entonces ha aumentado la velocidad y la intensidad de las actividades informales de la población que busca alternativas de salida por su propia cuenta.

Los empresarios han sido afectados de manera distinta por el cambio de modelo económico y por la crisis. Quienes mejor se adaptaron a los grandes cambios y a las ventajas de la economía globalizada fueron los grandes grupos internacionalizados, mientras que la apertura económica afectó severamente a los pequeños.

El impacto de la crisis en el ámbito espacial es también diferenciado. De acuerdo con los indicadores del empleo formal, los estados más afectados son los del norte del país que hacen frontera con Estados Unidos, donde se concentra la mayor parte de las industrias maquiladoras de exportación; la ciudad de México y el Estado de México, donde se localiza gran parte de las inversiones extranjeras y de las grandes empresas mexicanas; los estados que cuentan con plantas de la industria automotriz; algunos de los estados con mayor presencia de inversiones en turismo.

Por contraste, los estados de la república que perdieron menos personal ocupado son los más pequeños, con menor demografía y mayor proporción de población rural, y los estados que cuentan con menos empresas y personas en la economía formal. Estos 
estados han recibido también los menores montos de inversión extranjera; son los menos urbanizados y con los menores índices de desarrollo humano, en definitiva son los más pobres. Sin embargo, este indicador solo mide el empleo formal. Habrá que saber qué hacen los sectores que no son incorporados a la economía informal. Nuestra hipótesis es que tienen tres caminos: la migración a Estados Unidos, la economía informal y la economía ilegal.

Recebido em: 23.7.2010 Aprovado em: 02.9.2010

\section{Referencias}

ALBA VEGA, C. Tradición y modernidad, la industrialización de Jalisco. Guadalajara, Jalisco: Consejo de Cámaras Industriales de Jalisco, 2003.

. Los empresarios y la transición política. In: ORTEGA ORTIZ, R.Y. (Ed.). Caminos a la democracia. México: El Colegio de México, 2001)

. ¿Una alternancia sin alternativa? In: LOYOLA, R. (Coord) La disputa del reino. Las elecciones para gobernador en México, 1992. México: FLACSO / Juan Pablos editor / UNAM, 1997.

. La Coordinadora de Organizaciones Empresariales de Comercio Exterior: un caso de cooperación entre el sector público y el privado en México. In: MUÑOZ, O. (Ed.). Estado, empresarios, instituciones. Estrategias para la transformación productiva. Santiago de Chile: CEPAL / CIEPLAN, 1996.

. Los empresarios y el Estado durante el salinismo. In: Foro Internacional, Vol. 36, números 143-144, enero-junio 1996.

ALCÁZAR, M.A. Las agrupaciones patronales en México. México: El Colegio de México, 1970.

ARRIOLA, C. La Ley de Cámaras Empresariales y sus Confederaciones. In: Foro Internacional, Vol. XXXVII, Num. 4, octubre-diciembre 1997.

. Las organizaciones empresariales mexicanas contemporáneas.

In: Lecturas de política mexicana. México: Centro de Estudios Internacionales, El Colegio de México, 1977. 
. De la pérdida de confianza en el buen gobierno, 1979-1982. In: LOAEZA, R. \& SEGOVIA, R. (Comps.) La vida política mexicana en la crisis. México: El Colegio de México, 1987.

. Los empresarios y el Estado 1970-1982. México: UNAM Porrúa, 1988;

. La Concamin. In: ALBA VEGA, C. (Coord.) Historia y desarrollo industrial de México. México: Concamin, 1988.

AZIZ NASSIF, A. Chihuahua: historia de una alternativa. La jornada / CIESAS, 1994.

BARRAZA, L. \& BIZBERG, I. El Partido Acción Nacional y el régimen político mexicano. In: Foro Internacional, El Colegio de México, Vol. XXXI, núm. 3, enero-marzo 1991.

BIZBERG, I. Auge y decadencia del corporativismo. In: BIZBERG, I. \& MEYER, L. (Coords.) Una historia contemporánea de México: transformaciones y permanencias. México, D.F.: Océano, 2003.

BOYER, R. Formas del capitalismo y crisis financiera en los países emergentes, conferencia presentada en el Seminario Internacional: Dimensiones sociopolíticas y económicas de la crisis en los países emergentes. Enfoque pluridisciplinario y comparativo a partir de México. 11, 12, 13 de noviembre de 2009, México D.F.

BRIZ GARIZURIETA, M. El Consejo Mexicano de Hombres de Negocios, surgimiento y consolidación. México: Universidad Nacional Autónoma de México, 2002.

. El Consejo Mexicano de Hombres de Negocios en la transición hacia un nuevo modelo de desarrollo. Tesis de doctorado en Ciencia Política, FCPyS, UNAM, 2006

BUENDÍA LAREDO, J. Autoritarismo y participación empresarial: La Confederación Patronal de la República Mexicana, 1970-1988. Tesis de Licenciatura en Relaciones Internacionales, Centro de Estudios Internacionales, El Colegio de México, 1989.

CAMP, C.R. Entrepreneurs and politics in twentieth century Mexico. New York / Oxford: Oxford University Press, 1989;

CARTON DE GRAMMONT, H., Los empresarios agrícolas y el Estado. Sinaloa, 1893-1984. México: IIS-UNAM, 1990. 
CERUTTI, Mario. Burguesía y capitalismo en Monterrey, 1850-1910. Monterrey: Claves Latinoamericanas, 1983.

. Propietarios, empresarios y empresa en el norte de México: Monterrey: de 1848 a la globalización. México: Siglo Veintiuno, 2000.

CINTA, R. Burguesía nacional y desarrollo. In: El perfil de México en 1980, T. III, México: Siglo XXI Editores, 1972.

CONCHEIRO, E. El gran acuerdo. Gobierno y empresarios en la modernización salinista. México: Instituto de Investigaciones Económicas, UNAM / ERA, 1996.

CORREA, V.J.L. La liquidación de Fundidora Monterrey. In: Cuadernos Políticos, Núm. 47, 1986.

ELIZONDO, C. The making of a new alliance: the privatization of the banks in Mexico, Documentos de Trabajo, Estudios Políticos. México: Centro de Investigación y Docencia Económicas, 1993.

. In Search of Revenue: Tax Reform in Mexico under the Administrations of Echeverría and Salinas. CIDE, México / Nuffield College, Oxford. Documento mimeografiado, 1992.

FALOMIR, M.E. Los empresarios mexicanos ante la cuestión social. El caso de la Fundación del Empresariado Chihuahuense, un nuevo modelo de intervención social empresarial en el estado de Chihuahua. Tesis de Maestría en Ciencia Política, Facultad de Ciencias Políticas y Sociales, UNAM, 14 de mayo de 2010

FARÍAS HERNANDEZ, J.A. La fuga de capitales en México de 1989 a 1995. Este País. México, D.F., 1 de octubre de 1997.

FLORES TORRES, O.; SANDOVAL, J.A.O. \& MAÍZ, R.G. La industrialización en el Noreste de México.1850-1988. In: ALBA VEGA, C. (Coord.) Historia y desarrollo industrial de México. México: Concamin, 1988.

GONZÁLEZ, F.M. \& ALBA VEGA, C. Cúpulas empresariales y poderes regionales en Jalisco. Guadalajara: Universidad de Guadalajara, Cuadernos de Difusión Científica 14, 1989.

GUADARRAMA OLIVERA, R. Los empresarios norteños en la sociedad y la política del México moderno. Sonora /1929-1988, México El 
Colegio de México, El Colegio de Sonora, Universidad Autónoma Metropolitana, 2001.

GUADARRAMA, G. Empresarios y política: Sonora y Nuevo León, 1985. In: Estudios Sociológicos, Vol. 5, núm. 13, enero-abril, 1987.

GREEN, R. Lecciones de la deuda externa de México, de 1973 a 1997. De abundancias y escaseces. México: Fondo de Cultura económica y Fundación Colosio, A.C., 1998.

HERNÁNDEZ RODRÍGUEZ, R. Los problemas de representación en los organismos empresariales. Foro Internacional. v. XXXI, no. 3 [123], enero-marzo. 1991.

HAMILTON, N. México: Los límites de la autonomía del Estado. México, Ediciones ERA, 1984.

Hernández, R. Empresarios, banca y Estado. El conflicto durante el gobierno de José López Portillo, 1976-1982. México, FLACSO / Miguel Ángel Porrúa, 1988a.

HERRERA COLLADO, C. Empresarios y políticos. México, Instituto Nacional de Estudios Históricos de la Revolución Mexicana, Secretaría de Gobernación, 1996.

JACOBO, E. Las relaciones Estado-empresarios, ¿Hacia un nuevo pacto social?. In: HORCASITAS, R.P. \& LUNA, M. (Comps.). Las empresas y los empresarios en el México contemporáneo. México: Enlace - Grijalbo, 1991.

JACOBO, E. LUNA, M. \& TIRADO, R. Empresarios, pacto político y coyuntura actual en México. In: Estudios Políticos, nueva época, Vol. 8, Núm. 1, enero-marzo de 1989.

JUÁREZ, L. La organización empresarial en México durante el cardenismo e implicaciones internas e internacionales. México: Facultad de Ciencias Políticas y Sociales, UNAM, 1983.

. El proyecto Cardenista y la posición empresarial (1934-1938). Ponencia presentada al XX Congreso Mundial de Sociología, México, agosto de 1982

KAUFMAN PURCELL, S. The Mexican profit sharing decision. Politics in an authoritarian regime. Berkeley, Los Angeles, London: University of California Press, 1975. 
KATZ, F. Pancho Villa. México: Era, 1998.

LABASTIDA, J. (Comp.) Grupos económicos y organizaciones empresariales en México. México: Alianza Editorial MexicanaUNAM, 1986.

. Los grupos dominantes frente a las alternativas de cambio. In: El perfil de México en 1980. T. III, México: Siglo XXI Editores, 1972.

LESSARD, D. \& WILLIAMSON, J. Fuga de capitales y deuda del tercer mundo. México: Editorial Trillas, 1990.

LERDO DE TEJADA, C.S. \& GODINA HERRERA, L.A. El lobbying en México. México: Miguel Ángel Porrúa, 2004.

LUNA, M.L. Los empresarios y el cambio político. México, 1970-1987. México: IIS UNAM / ERA, 1992.

LUNA, M. \& TIRADO, R. El Consejo Coordinador Empresarial. Una radiografía. Cuadernos del Proyecto de Organizaciones Empresariales en México., Núm. 1, PCPyS - UNAM, México, 1992.

LUNA, M.; TIRADO, R. \& VALDÉS, F. Los empresarios y la política en México, 1982-1986. In: HORCASITAS, R.P. \& LUNA, M. (Comps.) Las empresas y los empresarios en el México contemporáneo. México: Enlace - Grijalbo, 1991;

LUNA, M.; MILLÁN, R. \& TIRADO, R. Los empresarios en los inicios del gobierno de Miguel de la Madrid. In: Revista Mexicana de Sociología, año XLVIII, Núm. 4, México, IIS, UNAM, Oct-Dic., 1985.

LUSTIG, N. México, Hacia la reconstrucción de una economía. México: El Colegio de México / Fondo de Cultura Económica, 2002.

MARQUES-PEREIRA, J. Competitividad del subdesarrollo y flexibilidad del trabajo en el norte de México. In: ALBA, C.; BIZBERG, I. \& D'ARC, H.R. (Comps.) Las regiones ante la globalización. Competitividad territorial y recomposición sociopolítica. México: CEMCA / ORSTOM / El Colegio de México, 1998.

MARTÍNEZ NAVA, J.M. Conflicto Estado-empresarios en los gobiernos de Cárdenas, López Mateos y Echeverría. México: Nueva Imagen, 1984. 
MAURO, F. Le développement économique de Monterrey, 1890-1960. In: Caravelle. Institut d' Etudes Hispaniques, Hispanoamericaines et Luso-Brésiliennes. Université de Toulouse, 1964.

MIZRAHI, Y. A New Conservative Opposition in Mexico: The Politics of Entrepreneurs in Chihuahua (1983-1992). Tesis de Doctorado en Ciencia Política, Universidad de California, Berkeley, 1994.

. La nueva oposición conservadora en México: la radicalización política de los empresarios norteños. In: Foro Internacional, Vol. XXXII, Núm. 5 (130), octubre-diciembre de 1992.

MONTESINOS, R. El discurso político de las organizaciones empresariales. La transición mexicana desde la teoría de los sistemas. México: UAM-I, 2007

MOSK, S.A. La revolución industrial en México. Problemas agrícolas e industriales de México. Vol. III, Núm. 2, abril-junio de 1951.

MUÑOZ COTA, J. El Consejo Coordinador Empresarial en el sexenio de Vicente Fox. Tesis de Maestría en Ciencia Política, Centro de Estudios Internacionales, El Colegio de México, México, abril, 2009.

Nuncio, A. El Grupo Monterrey. México, Editorial Nueva Imagen, 1982.

ORTEGA RIQUELME, J.M. Acuerdos tripartitas y gobernanza económica en el México de fin de siglo. Foro Internacional, Vol. XLVI - Núm. 2 (184), abril- junio de 2006.

ORTIZ RIVERA, A. Consejo Mexicano de Hombres de Negocios: ¿Poder tras la silla presidencial?. Tesis de maestría en sociología política, México, Instituto Dr. José María Luis Mora, México, 1998

PADILLA, C. Todo queda en familia. Los bodegueros del mercado de abastos de Guadalajara. Guadalajara: Universidad de Guadalajara, 1996.

POLANCO, J.M. Las organizaciones empresariales en la coyuntura del GATT. Tesis de maestría, Facultad Latinoamericana de Ciencias Sociales, México, junio de 1990.

POZAS, M.A. Estrategia internacional de la gran empresa mexicana en la década de los noventa. México: El Colegio de México, Centro de Estudios Sociológicos, 2002. 
PUGA, C. Los empresarios organizados y el Tratado de Libre Comercio de América del Norte. México: Universidad Nacional Autónoma de México / Migué Ángel Porrúa, 2004, 288 páginas.

PUGA, C. Las organizaciones empresariales en la negociación del Tratado de Libre Comercio. In: TIRADO, R. (Coord.) Los empresarios ante la globalización. México: Cámara de Diputados del $\mathrm{H}$. Congreso de la Unión / Instituto de Investigaciones Jurídicas e Instituto de Investigaciones Sociales UNAM, 1994.

. Los empresarios ante la nacionalización bancaria. In: LABASTIDA, J. (Coord.) Grupos económicos y organizaciones empresariales en México. México: Alianza Editorial Mexicana / UNAM, 1986.

REYES PONCE, A. Coparmex. Su origen y desarrollo. Hacia los próximos 50 años. México, D.F. Coparmex, 1979.

REVEL-MOUROZ, J. Aspects de l'industrialisation à Medellin, Guadalajara et Monterrey. In: Travaux et memoires de l'Institut des Hautes Etudes de l'Amérique Latine. L'Espace mexicain, Questions d'actualité. Tomo II, Paris, 1976

ROUSSEAU, I. México, ¿Una revolución silenciosa? México: El Colegio de México, 2001.

RIVIÈRE D'ARC, H. Le Nord-Mexique et-il atypique? Le cas du Chihuahua. Problèmes d'Amérique Latine. Spécial Mexique, La Documentation Française, avril-juin, 1992.

SAMANIEGO, N. El empleo y la crisis. Precarización y nuevas "válvulas de escape". In: Economía UNAM, mayo - agosto 2010.

SERNA, M.G. "Aquí no hay seguro contra crisis..." Empresarias, empresas y hogares en dos zonas metropolitanas de México. México: CIESAS / Instituto Mora, 2003.

SHADLEN, K.C. Democratization Without Representation. The Politics of Small Industry in Mexico: Penn State Press, 2004.

SHAFER, R.J. Mexican Business Organization, History and Analysis. New York: Syracuse University Press, 1973.

STORY, D. Industrial Elites in Mexico, Political Ideology and Influence. In: Journal of Inter American Studies and World Affairs. August, 1983. 
TIRADO, R. Los industriales, la política y el fin del proteccionismo industrial. Tesis de Doctorado en Ciencias Políticas y Sociales, Programa de Posgrado en Ciencias Políticas y Sociales, Universidad Nacional Autónoma de México, México, D.F., 2004.

. El poder en las cámaras industriales de México. Foro Internacional, Vol. XLVI - Núm. 2 (184), abril- junio de 2006.

. Semblanza de las organizaciones empresariales. In: Estudios políticos, FCPyS UNAM, marzo, 1984.

TIRADO, R. \& LUNA, M. La politización de los empresarios mexicanos (1970-1982). In: LABASTIDA, J. Grupos económicos y organizaciones empresariales en México. México: Alianza Editorial Mexicana-UNAM, 1986.

TORRES, B. Historia de la Revolución Mexicana, 1940-1952. Hacia la utopía industrial. México: El Colegio de México, 1984.

TORRES, B. \& FALK, P.S. (Coords.): La adhesión de México al GATT. Repercusiones internas e impacto sobre las relaciones MéxicoEstados Unidos. México: El Colegio de México, 1989.

TOURAINE, A. Les Sociétés dépendantes. Essais sur l'Amérique latine. Paris: Duculot, 1976.

VALDÉS UGALDE, F. Autonomía y Legitimidad. Los empresarios, la política y el Estado en México. México: Siglo XXI, 1997.

. Una aproximación al análisis de las relaciones entre empresarios y gobierno en México, 1970-1976. In: LABASTIDA, J. Grupos económicos y organizaciones empresariales en México. México: Alianza Editorial Mexicana-UNAM, 1986.

VALENCIA LOMELÍ, E. Política social mexicana: modelos a debate y comparaciones internacionales. In: VALENCIA LOMELÍ, E; GENDREAU, M. \& TEPICHÍN, A.M. (Coords.) Los dilemas de la política social. ¿Cómo combatir la pobreza? Guadalajara: Iteso-UIA-Universidad de Guadalajara, pp. 119-156.

VANGSTRUP, U. Centros de servicios empresariales y competitividad de un cluster industrial: el caso de la industria de prendas de vestir en Moroleón y Uriangato, Guanajuato. In: ESTRADA, M. \& LABAZÉE, P. (Coords.) Los espacios de la globalización. Mutaciones, 
articulaciones, interacciones. Acercamiento comparativo a partir del Bajío (México). México: CIESAS (en prensa).

VELLINGA, M. Industrialización, Burguesía y Clase Obrera en México. México: Siglo XXI, 1979; Abraham Nuncio, El Grupo Monterrey, México, Editorial Nueva Imagen, 1982.

VIZCAYA CANALES, I. Los orígenes de la industrialización de Monterrey (1867 1920), Monterrey, Librería Tecnológico S.A. 1971.

VILLA LEVER, L. 50 años de la Conaliteg: Cambios y permanencias en la educación mexicana. México. D.F., Comisión Nacional de los Libros de Texto Gratuitos (CONALITEG), 2010.

, Los libros de texto gratuitos: la disputa por la educación en México. Universidad de Guadalajara: Guadalajara, 1988.

WASSERMAN, M. Capitalistas, caciques y revolución. La familia Terrazas en Chihuahua, 1854-1911. México, Enlace / Grijalbo, 1988.

ZAPATA NOVOA, J. Tercos y triunfadores de Monterrey; los retos de Monterrey en el siglo XX. Monterrey: Castillo, 1993.

ZAPATA NOVOA, J. La muerte de Fundidora. Reconversión de la cultura industrial mexicana. México: Noriega Editores/Editorial Limusa, 1989.

ZABLUDOWSKI, G. Proposiciones para el estudio de las relaciones entre Estado y empresarios durante el periodo presidencial de Miguel Alemán. In: Estudios Políticos, núm. 1, Vol. 3, enero-marzo de 1984.

\footnotetext{
Abstract

Entrepreneurs, politics and society in Latin America: the Mexican case

This text examines the relationships between entrepreneurs and the State in Mexico, from a long range perspective, in order to show that the political participation of economic actors has both common traits and singularities in relation to entrepreneurs in other Latin American countries. The paper is developed around an attempt to answer the following five questions: What characteristics do entrepreneurs acquire as they attempt to fit into a political system that emerges out of social revolution? What importance does the Mexican Council of Businessmen have in the relationship between businessmen and the State? How do entrepreneurs participate
} 
in political transition? What type of conduct did entrepreneurs exhibit in the 2006 presidential elections? How has economic crisis affected firms and entrepreneurs in Mexico, and society as a whole?

Keywords: entrepreneurs and politics, entrepreneurs and political transition, power groups, entrepreneurs and crisis. 
